\title{
Análisis crítico del discurso sobre conflicto armado y desarrollo en los presidentes Álvaro Uribe Vélez y Juan Manuel Santos en Colombia entre los años 2002 y $2013^{*}$
}

\section{Critical discourse analysis on armed conflict and development in Presidents}

Álvaro Uribe Vélez and Juan Manuel Santos in Colombia between 2002 and 2013

Carlos Javier Pabón Arévalo**

Recibido: 23 de junio de 2015

Revisado: 6 de julio de 2015

Aprobado: 2 de febrero de 2016

\section{Resumen}

El artículo presenta un análisis discursivo sobre conflicto armado y desarrollo en textos de los presidentes Álvaro Uribe Vélez y Juan Manuel Santos entre los años 2002 y 2013.

* Este artículo es producto de la tesis de grado de la Maestría en Estudios y Gestión del Desarrollo, Universidad de la Salle. Bogotá, Colombia. Cómo citar este artículo: Pabón, C. (2015). Análisis crítico del discurso sobre conflicto armado y desarrollo en los presidentes Álvaro Uribe Vélez y Juan Manuel Santos en Colombia entre los años 2002 y 2013. Revista CIFE, 17(27), 55-10

** Psicólogo, Universidad Nacional de Colombia. Magister en Estudios y Gestión del Desarrollo de la Universidad de la Salle. 
Busca identificar la manera en que se instituyen y operan estos discursos. Realiza un abordaje cualitativo, para lo cual se utiliza como instrumento el análisis crítico del discurso y el interés se concentra en los tres conceptos principales de su estructura conceptual: identidad nacional, poder e ideología. Además, orienta la metodología de análisis hacia la dimensión de practica social formulada por Fairclough en el marco de su modelo tridimensional de análisis crítico del discurso. Mediante esta metodología, se demuestra que existen diferencias relevantes entre las estructuras y las estrategias discursivas de cada actor, con las cuales se han legitimado formas de proceder en sus gobiernos.

Palabras clave: Conflicto armado, desarrollo, análisis crítico del discurso.

Glasificación JEL: A12, O10, Z13

\begin{abstract}
The article presents a discourse analysis on armed conflict and development in texts of Presidents Álvaro Uribe Vélez and Juan Manuel Santos between 2002 and 2013. It seeks to identify how these discourses are instituted and operated. It makes a qualitative approach, for which it uses the critical discourse analysis as tool and the interest focuses on three main concepts of its conceptual structure: national identity, power and ideology. In addition, the analysis methodology is oriented towards the dimension of social practice expressed by Fairclough as part of his three-dimensional model of critical discourse analysis. Using this methodology, the significant differences between the structures and the discursive strategies of each actor are shown, with which the ways to proceed in their governments have been legitimized.
\end{abstract}

Keywords: Armed conflict, development, critical discourse analysis.

Classification JEL: A12, O10, Z13 


\section{Introducción}

El conflicto armado interno en Colombia actualmente es el más antiguo de la región. Por esta longevidad, ha sufrido transformaciones acontecidas como mecanismos de adaptación y vigencia. Camacho (1991) realiza un análisis de las continuidades y rupturas de los aspectos más fundamentales de la violencia en el país y señala que “(...) más allá del hecho de muerte, se manifiestan diferencias tan fuertes que invalidan la idea de que la violencia es una sola y que no varía en el tiempo". Para el autor, existen circunstancias históricas y específicas que determinan la instalación de nuevas dinámicas de operación de la violencia, por lo que, por las modificaciones del escenario en que se ha desarrollado - cambios sociales y económicos, narcotráfico, corrupción--, no es posible afirmar que la violencia de los años cincuenta es la misma de los años ochenta, los noventa o la actual.

Fisas (2005) señala que todo conflicto es dinámico y que, así mismo, los investigadores y formuladores de política pública deben ajustarse a esta condición cambiante en sus análisis y diseños. De esta manera, el autor señala:

Esta innovación cíclica tiene sus explicaciones: los conflictos adquieren diferente personalidad a medida que avanzan los años (los de ahora no pueden abordarse como los de la guerra fría), quienes analizan los conflictos también evolucionan, el contacto entre teoría y observación directa es más intenso y la influencia de otras disciplinas o maneras de ver también es más profunda hoy que ayer. (p. 1).

Ante este panorama de variación progresiva, la discusión y el abordaje del asunto del conflicto armado en el país está vigente y se sigue presentando como pertinente, más aún cuando, en el marco de dicho conflicto, se ponen en juego nociones, ideas y condiciones para la proyección de desarrollo del país. Lo anterior sugiere que las construcciones discursivas sobre conflicto armado y desarrollo en el país también sufren transformaciones en el tiempo, dado que el contexto se cambia constantemente y se traduce en nuevos modos de política, en nuevas prácticas sociales y discursivas, y en nuevas expresiones de necesidades de la nación.

El objetivo general de esta investigación es dilucidar los mecanismos por los cuales se instituyen y operan los discursos sobre conflicto armado y desarrollo de los presidentes Álvaro Uribe Vélez y Juan Manuel Santos en Colombia en el periodo comprendido entre los años 2002 y 2013. Poder evidenciar el funcionamiento y la operación de estas estrategias discursivas permite proponer un dispositivo explicativo que dé cuenta de la naturaleza de las acciones de los gobiernos en materia de seguridad y desarrollo, reconociendo el carácter determinante de los discursos sobre las prácticas sociales y viceversa.

Los objetivos específicos están formulados con base en los tres pilares fundamentales del análisis crítico del discurso: identidad (historia), poder e ideología, puestos en relación 
con las dos categorías de interés para esta investigación (conflicto armado y desarrollo). Estos están formulados de la siguiente forma:

- Analizar los modos de enunciación acerca de las identidades nacionales presentes en los discursos de los presidentes Álvaro Uribe Vélez y Juan Manuel Santos.

- Establecer las estructuras de poder para instalar un modelo de desarrollo en los gobiernos de Álvaro Uribe Vélez y Juan Manuel Santos desde el análisis crítico del discurso.

- Develar los sistemas ideológicos sobre conflicto armado interno y desarrollo presentes en los discursos de los presidentes Álvaro Uribe Vélez y Juan Manuel Santos.

El análisis de los textos se realiza a la luz de una mirada cualitativa. La apuesta de esta investigación es identificar, por medio del análisis crítico del discurso, la manera como se han venido produciendo y transmitiendo discursos hegemónicos que enmarcan políticas de juicio de la realidad, regímenes de verdad que operan en un trascurso de tiempo, como ejercicio y técnicas de gobierno, para impulsar e imponer, en función del conflicto armado, unas políticas, planes o ideas de desarrollo.

Siguiendo a Wodak y Meyer (2003), el presente estudio busca realizar los análisis de las estructuras discursivas de los actores en relación con los tres ejes fundamentales del análisis crítico del discurso (ACD) planteados por esta autora, a saber: identidad nacional (como un elemento de la historia), poder e ideología. Por otro dalo, para obtener los resultados de esta investigación, se recurre al modelo tridimensional de análisis crítico del discurso formulado por Fairclough (1989). Este modelo presenta tres niveles de análisis: 1) textual, que es de tipo descriptivo, 2) práctica discursiva, de tipo interpretativo y 3) práctica social, de tipo explicativo. Así, se trata de un esquema de análisis que va de lo textual a lo contextual. Es necesario aclarar que, aunque se realizaron los análisis de los textos en estas tres dimensiones, los resultados y las conclusiones del presente estudio concentran su atención en los elementos de la dimensión práctica social, en la cual se incluyen los elementos de identidad nacional, poder e ideología mencionados anteriormente.

\section{Marco teórico}

\subsection{Violencia}

La violencia se puede entender como un constante ejercicio de poder con el que se transgreden límites establecidos en las relaciones sociales, sean visibles o no sus efectos. Estos límites pueden estar establecidos por normatividad, leyes o acuerdos que, al ser transgredidos o estar en amenaza de serlo, generan daños físicos o psicológicos en quien ostenta dicha protección. Al respecto, Buvinic, Morrison y Michael (1999) señalan que 
"la violencia dentro y fuera del hogar es un asunto de derechos humanos... Un acto de violencia puede o no infringir la legislación existente y, en consecuencia, puede o no ser catalogado de 'criminal' por el sistema de justicia criminal". Por lo anterior, se infiere que pueden existir actos basados en la transgresión de algunos límites que no logran ser establecidos en el interior del sistema de justicia criminal, pero que no por ello dejan de ser actos violentos.

Por otro lado, Fisas (1998) introduce otra definición de violencia que tiene en cuenta aspectos más próximos a la prevención, de gran incidencia para reducir sus riesgos:

Por violencia podemos entender el uso o [la] amenaza de uso de la fuerza o potencia, abierta u oculta, con la finalidad de obtener de uno o varios individuos algo que no consienten libremente, o de hacerles algún tipo de mal (físico, psíquico o moral). La violencia, por lo tanto, no es solamente un determinado tipo de acto, sino también una determinada potencialidad. No se refiere solo a una forma de "hacer", sino también de "no dejar hacer", de negar potencialidad. (Fisas, 1998, p. 24).

Así, existen diversas nociones sobre violencia. Estas suelen estar basadas en categorizaciones de acuerdo con sus formas de ocurrencia o sus fuentes. Según Galtung (1990), la violencia logra ser trasversal en todas las esferas sociales, en lo económico, lo político y lo cultural. Dichos escenarios de incidencia permiten categorizar la violencia en dos líneas: violencia cultural y violencia estructural.

La categoría de violencia cultural, como condición de posibilidad, se refiere a escenarios simbólicos como la religión, la ideología, el arte, el lenguaje, la ciencia, los medios de comunicación y la educación, que constituyen los contextos de producción de subjetividad y los instrumentos de mediación en todo proceso de socialización y conocimiento. Estos, a su vez, son elementos de legitimación de los procesos de violación de derechos y de violencia.

Referente a la violencia estructural como privación de satisfacción de necesidades, se establecen dos tipos de violencia: en la vertical están inmersas la represión política, la explotación económica o la alienación cultural, cuyo efecto está en dirección de violentar las necesidades de libertad, de bienestar, etc.; y, por otro lado, está la horizontal, la cual trasgrede los valores de identidad nacional, de colectivo y de territorio (Galtung, 1990, p. 294). Sin duda, no hay un orden jerárquico, sino de transversalidad y transposición constantes de una y otra, inmersas en escenarios donde coexisten la violencia estructural y la cultural.

Moser (2000), por su parte, plantea la necesidad de abordar el tema de la violencia en la región desde un marco de referencia que introduce tres categorías: violencia política, económica y social, cada una definida por una diferente motivación primaria, ya sea mantener, mediante el uso de la fuerza o la violencia, el poder político, económico o social, respectivamente. Sin embargo, estos tipos de violencia no necesariamente son 
excluyentes entre sí. Esto implica que, de acuerdo con el caso, se pueden establecer límites difusos entre las tres categorías, dándose en ocasiones una superposición de estas.

Buscando explicaciones alternativas, el análisis económico ofrece una contribución importante en la identificación de las estructuras de incentivos que logran explicar en cierto modo los comportamientos violentos. En este sentido, Gary Becker (1968) introduce el concepto de "economía del crimen", mediante el cual busca explicar cómo los criminales son agentes racionales cuyo comportamiento puede entenderse como la respuesta óptima a los incentivos existentes. Es decir, se considera que los criminales harán extensivas sus actividades criminales siempre que disminuya el tamaño o la probabilidad del castigo y, de este modo, aparte de las preferencias de los delincuentes potenciales y del coste de oportunidad de sus actividades, el tipo y el número de delitos dependerán de la eficiencia de las instituciones encargadas de administrar justicia. Se esperaría que, a mayores niveles de desarrollo, el sistema de seguridad social y justicia penal de un país esté más fortalecido, dándose condiciones para lograr reducciones significativas de la violencia.

\subsection{Teoría del conflicto}

Hablar de conflicto exige entrar en un espectro de análisis amplio y, a su vez, ambiguo, dado que se suele hablar indiferenciadamente de conflicto, violencia, guerra, crimen, confrontación, etc. Para definirlo mejor, se requiere conocer las causas materiales, simbólicas y estructurales que lo constituyen y que son condiciones de posibilidad.

Existe generalmente una visión abiertamente negativa sobre la ocurrencia de conflictos, y esa interpretación descarta la posibilidad de reconocer la potencialidad positiva que puede presentar el conflicto en determinado contexto. Fisas (2005) plantea algunas distinciones importantes en la conceptualización del conflicto. Al respecto, expone: “(...) bajo ningún concepto debemos olvidar la expresión no belicista de los conflictos, y en particular, cuando pretendemos vincular el estudio de los conflictos con la cultura de la paz" (p. 1).

Para Fisas (1998), el conflicto tiene naturaleza netamente social, dado que se construye en el marco de las relaciones y vínculos entre los seres humanos. Según el autor, este se debe diferenciar de la violencia, pues puede haber conflictos sin violencia, pero no violencia sin conflicto. Dependiendo de sus motivaciones, formas de abordaje e intentos de solución, un conflicto puede ser positivo o negativo. Si logra ser transformado mediante el diálogo hasta ser superado, entonces podría hablarse de paz. Por el contrario, si se mantienen las incompatibilidades iniciales entre las partes, lo más probable es que se presenten disputas cada vez más intensas, hasta llegar finalmente a las confrontaciones armadas. 
Por otro lado, Bartos y Werh (2002) definen el conflicto como una situación en la que los actores utilizan un comportamiento o una conducta de conflicto entre sí para alcanzar metas incompatibles y/o para expresar su hostilidad, sin embargo, hacen algunas claridades. Un actor puede ser un grupo de personas, por lo tanto, allí se refiere a un comportamiento del grupo. Además, debe hacerse la distinción entre conflicto y competición. En el primero se dan conductas de contienda, mientras en la segunda se establecen otras conductas que no implican el deterioro o la afectación del oponente. También es necesaria una comprensión de la existencia tanto de conflictos violentos como de conflictos no violentos. Por último, el autor señala que la incompatibilidad en el conflicto se da en la medida en que las metas de los diferentes actores sean imposibles de lograr de manera simultánea o cuando se pueden cumplir, pero la recompensa para cada actor es desproporcionada.

Wallensteen (2007) plantea que el conflicto es más que un asunto de comportamiento de las partes. Según el autor, de ser así, el conflicto terminaría cuando esta conducta cesase. Un alto a las hostilidades no necesariamente implica un fin del conflicto. Podría ser, más bien, un interludio. Así, el asunto de fondo son las causas que originan el conflicto. Ninguna de las partes cesará sus acciones hasta ver algún tipo de movimiento en lo referente a estas. Y las causas son las posiciones incompatibles asumidas por los actores en un principio. Sin embargo, esta incompatibilidad está dada por la falta de recursos para poder alcanzar al mismo tiempo las metas distintas. De existir abundancia de recursos, se podría prevenir o solucionar la situación. Por último, para completar la definición, el autor resalta el papel de los actores que son agentes activos, hacen análisis e interpretaciones sobre sus necesidades de supervivencia y sobre si estas entran en conflicto con otras.

Así, al conflicto no se le puede asignar una definición única y unidimensional, es un concepto que se funde con otros que constituyen un espectro temático. Se ignora que el conflicto puede ser no solo una respuesta negativa ante una situación, sino que también puede ser entendido como una ocasión de transformación o un suceso intermedio entre lo estable y el desequilibrio. Como un "fenómeno contradictorio de construcción y de destrucción", y, de igual manera, como "causa y expresión de las más diversas transformaciones de la historia” (Martínez, 2001, p. 62).

Este argumento plantea el conflicto como un desequilibrio en el sistema, necesario para que el sistema busque nuevos estados de equilibrio. En un sistema, un desequilibrio producto de la incorporación de nuevos factores que complejizan su funcionamiento genera desestabilizaciones que llevan a la estructura a buscar una regulación para poder obtener una nueva condición de equilibrio.

Wallensteen (2007) muestra puntos de vista que defienden la necesidad de la violencia y la guerra, argumentando la existencia de condiciones insoportables que es necesario 
detener a toda costa. Sin embargo, según el autor, los resultados de la guerra contradicen la esperanza de un futuro mejor que la pudo haber motivado. Es necesario, primero, agotar todas las vías posibles para hallar una solución pacífica antes de argumentar a favor de una confrontación armada. Es así como el conflicto se puede considerar como una "zona templada" entre el furor de la guerra y la ansiada condición de paz, es un fenómeno que está latente en las diferentes relaciones sociales que en algún momento lo desencadenan y lo sostienen.

También existen propuestas de categorización del conflicto. Según Ian Doucet (1998, p. 65), "el conflicto puede surgir cuando las partes en disputa no están conformes con la distribución tanto de recursos materiales como de los simbólicos", entendiendo los primeros como medios por los cuales se busca una estabilidad o la cobertura de las necesidades básicas, y los segundos como el reconocimiento que se quiere obtener para una mayor participación dentro de una sociedad.

Alfred Hirschman (1994) pone acento en la relación establecida entre conflicto y democracia, y los efectos integradores o disgregadores de los conflictos a nivel de vínculos sociales y comunitarios. Así, plantea dos clases de conflictos: indivisibles y divisibles. Los primeros son un factor de desintegración social y de la estructura democrática, pues implican situaciones muy complejas y difíciles de resolver por la vía de la negociación, dada su naturaleza excluyente. O se gana o se pierde. Se trata de la victoria completa de una parte sobre la otra. En esta categoría se incluyen conflictos de corte identificativo, como los religiosos, étnicos o ideológicos, que implican rupturas radicales entre colectivos que finalmente entran en disputa. En este tipo de conflictos se establecen formaciones identificativas del tipo "nosotros" y "los otros" (o el resto - lo diferente), que suelen abrir la brecha entre las partes e impiden una negociación.

Los conflictos divisibles se refieren a la inclusión de elementos de tipo económico o de gustos, los cuales se pueden negociar. Hirschman los considera integradores por cuanto aceptan parcial o totalmente las demandas sociales por vía de la participación de quienes están excluidos, de cara a asegurar la equidad de los derechos individuales. Son estos, precisamente, los que Hirschman considera como los conflictos de las "modernas democracias", ya que la injusticia, la inequidad etc., crean una demanda de derechos, acciones y participación que piden que se incluyan cosas que un momento quedaron excluidas, por medio de la cohesión comunitaria (Martínez, 2001, p. 63)

\subsection{Conflicto armado}

El Comité Internacional de la Cruz Roja-CICR (2008), con base en el DIH, hace una distinción entre dos tipos de conflictos armados: internacionales y no internacionales. En el plano de lo jurídico, no existe tipología diferente a estas dos mencionadas. Las definiciones se plantean de la siguiente forma: 
A. Existe un conflicto armado internacional cuando se recurre a la fuerza armada por parte de dos o más Estados.

B. Los conflictos armados no internacionales son enfrentamientos armados prolongados que ocurren entre fuerzas armadas gubernamentales y las fuerzas de uno o más grupos armados, o entre estos grupos, que surgen en el territorio de un Estado (partícipe en los Convenios de Ginebra). El enfrentamiento armado debe alcanzar un nivel mínimo de intensidad y las partes que participan en el conflicto deben poseer una organización mínima (p. 6).

Así, respecto de los conflictos armados no internacionales, el CICR señala que es necesario hacer una distinción de esta categoría a la luz de la jurisprudencia complementaria existente. Colombia ha sido firmante de todos estos convenios.

El artículo 3 común a los cuatro Convenios de Ginebra establece que en un conflicto armado no internacional debe haber enfrentamientos en el interior del territorio nacional entre las fuerzas armadas gubernamentales y grupos armados no gubernamentales, o bien, solo entre estos grupos no gubernamentales. Además, hace una diferenciación entre los combates propios del conflicto y eventos de otro carácter, como motines, disturbios interiores y vandalaje. Así, se hace necesario establecer un umbral para poder determinar el caso. Este nivel mínimo implica acciones colectivas y que el gobierno determine el uso de las fuerzas militares en vez de las fuerzas policiales. El artículo establece, además, que los grupos no gubernamentales deben tener una organización, obedecer a un orden jerárquico.

El artículo 1.o del Protocolo Adicional II es complementario al artículo presentado anteriormente y puntualiza sobre algunos aspectos. Este excluye situaciones en las que solo se encuentran en confrontación grupos armados no gubernamentales. Además, debe ser demostrable que dichos grupos armados poseen una organización con un mando responsable y tienen control territorial sobre zonas, que les permiten realizar acciones militares de manera constante.

Otra definición, la del Reporte Anual de Conflictos Armados, del Proyecto Ploughshare (2014), señala que el umbral mínimo para la clasificación de un evento como conflicto armado interno es la ocurrencia de al menos mil muertes durante el curso del conflicto. En esta confrontación, al menos una de las partes es un grupo gubernamental, o hay una o más facciones armadas tratando de obtener el control parcial o total del Estado. Así, el conflicto es incluido en la lista anual del reporte cuando alcanza la cifra de muertes mencionada, reportándose el año en el que se registran las primeras muertes por este.

Según el reporte de 2013, el conflicto en Colombia está dirigido a ostentar un control estatal. El Gobierno colombiano y sus Fuerzas Militares, en asociación con los grupos paramilitares y con el auspicio económico del Gobierno de Estados Unidos, combaten contra las guerrillas izquierdistas de las FARG y el ELN. Este reporte recoge las cifras 
emitidas por el Centro de Memoria Histórica, en el que se afirma que cerca de 220000 personas han muerto por el conflicto entre 1958 y 2013.

Además, el PRIO (2013) define conflicto armado como "una incompatibilidad impugnada, que se refiere al gobierno y/o territorio donde el uso de la fuerza armada entre dos partes, de las cuales al menos una es el gobierno de un Estado, se traduce en al menos 25 muertes en combate". Esta es una cifra de muertes por año y por diada, dado que un conflicto puede llegar a tener más de una diada. En el caso de Colombia, actualmente existen dos diadas (gobierno/FARC - gobierno/ELN). Según esta definición, puede haber dos tipos de incompatibilidad. La primera, concerniente al gobierno, es decir, al tipo de sistema político, que puede implicar el reemplazo del gobierno total o parcialmente. La segunda, referente al territorio; para el caso de conflicto interno, control de algunas zonas, cesión y autonomía.

Respecto de este último tipo de incompatibilidad, el Informe de Desarrollo Humano para Colombia (2003) plantea un escenario de control geopolítico para el conflicto armado en el que se establece una relación desigual entre las regiones del país, como una dinámica de centro-periferia. Así, hubo una formación de regiones aisladas por falta de presencia estatal, y este vacío fue llenado por grupos armados ilegales, como las guerrillas de izquierda y otros. Así, podría afirmarse que el caso de Colombia incluye los dos tipos de incompatibilidades mencionados en el párrafo anterior.

\subsection{Desarrollo}

Una presentación completa de las escuelas del desarrollo en este documento es imposible, dada la amplia y extensa producción teórica existente sobre el tema. Sin embargo, sí es de mi interés referirme de manera general a las corrientes de desarrollo más importantes, para tener un contexto o marco de referencia que impulse posteriores análisis.

\subsubsection{Teorías del desarrollo}

Las primeras escuelas del desarrollo fueron posteriores a la Segunda Guerra Mundial en 1945. A partir de allí se dio el surgimiento de la teoría de la modernización, que se refiere a los beneficios de los avances científicos, al progreso industrial para la mejora y al crecimiento de lo que se denominó como las áreas subdesarrolladas. A partir de entonces se consolidó un nuevo discurso hegemónico que organizó el mundo entre desarrollados y subdesarrollados. Como señala Arturo Escobar (2005, p. 18): "La teoría de la modernización inauguró, para muchos teóricos y élites mundiales, un periodo de certeza bajo la premisa de los efectos benéficos del capital, la ciencia y la tecnología". Estados Unidos, como uno de los grandes vencedores en la Segunda Guerra Mundial, asumió el liderazgo de esta reorganización geopolítica y enarboló la bandera del crecimiento 
económico como indicador de desarrollo y con la intención de modernizar las sociedades no industriales y subdesarrolladas.

Pero este discurso debía estar provisto de un andamiaje teórico económico para que pudiese operar. Además de la teoría keynesiana, que venía siendo influyente desde años atrás, comenzaron a establecerse diferentes aportes que fortalecieron la teoría del crecimiento, potentemente ligada a la propuesta de la modernización. Preston (1999, pp. 212-213), por ejemplo, ubica como uno de los principales representantes de este refuerzo teórico a Walt Rostow, quién en 1960 estableció una teoría de las etapas del crecimiento económico para las sociedades del mundo. Según esta elaboración, existen cinco etapas en las que una sociedad evoluciona hasta llegar a su nivel de desarrollo máximo, partiendo desde una etapa de menor desarrollo, como la de la sociedad tradicional (agrícola y con producción limitada), hasta un nivel de consumo masivo (sociedad industrializada y con estabilidad en su bienestar social). Indica el grado de una sociedad que no ha logrado obtener el desarrollo completo, ubicándola en una etapa intermedia.

Esta teoría es criticada ampliamente por los teóricos de la dependencia, quienes se refieren a la existencia de sesgos importantes al descuidar asuntos históricos en estas formulaciones. Según Preston (1999, p. 211), teóricos como A. G. Frank critican la manera como se establece la convención del estado inicial de estas etapas de desarrollo, realizando una abolición de la historia de los países del tercer mundo. La teoría de Rostow plantea que hay un inicio desde el cual las sociedades hoy desarrolladas partieron, y que eso implicaría que aquellas sociedades llamadas "subdesarrolladas" se mantuvieron en ese punto de partida, sin reconocérseles lo que de allí hacia atrás existiera como parte de su historia.

La escuela de la dependencia ha afirmado que los países "subdesarrollados" tienen unas particularidades propias y, de esta manera, la teoría de la modernización no es relevante para el entendimiento de estas condiciones. Así, el subdesarrollo no es producto de carencias de capital y tecnología, sino resultado de la acumulación capitalista que genera los polos centro-periferia.

En la década de los sesenta y en la de los setenta hubo una respuesta de los países señalados como subdesarrollados, plantándose la teoría de la dependencia. Desde esta corriente, el asunto de la mayor inversión y ahorro es necesario, mas no suficiente para alcanzar el bienestar en la región, dado que las relaciones desiguales entre naciones y sectores sociales hace que los beneficios y el bienestar no sean generales. "El subdesarrollo no es consecuencia de la supervivencia de instituciones arcaicas, de la falta de capitales en las regiones que se han mantenido alejadas del torrente de la historia del mundo, por el contrario, el subdesarrollo ha sido y es aún generado por el mismo proceso histórico que genera también el desarrollo económico del propio capitalismo" (Gunder-Frank, 1963). El subdesarrollo es, entonces, el resultado de la evolución histórica desigual propia del 
sistema imperante, de relaciones entre países ricos (centro) y países pobres (periferia), en el que se dan dinámicas de explotación de los primeros sobre los segundos, siendo este un estado inducido por fuerzas externas que operan a nivel internacional.

La CEPAL formuló, entonces, la política de industrialización por sustitución de importaciones, que implica incentivar la industrialización de manera endógena por medio de la intervención del Estado y le creación de subsidios, generar estrategias de protección de la producción interna, como impuestos a la importación y políticas cambiarias o monetarias que permitan este fortalecimiento interno.

Posteriormente, en la década de los ochenta, el ascenso de gobiernos conservadores en Estados Unidos, Gran Bretaña y Canadá se constituyó como escenario propicio para el resurgimiento de ideas neoclásicas sobre mercado libre, reducciones de los controles y de los impuestos, que finalmente terminaron en la formulación del Consenso de Washington. La contrarrevolución neoclásica "fue encabezada por autores como Belá Balastasa, Anne Krueger o Ian Malcolm David Little, quienes criticaron con virulencia el enfoque de las necesidades básicas, la intervención gubernamental y las estrategias de industrialización por sustitución de importaciones promovidas por las teorías heterodoxas del desarrollo" (Mogrovejo, 2010).

Así, el estado de subdesarrollo de una región se debe a la intervención torpe del Estado en los procesos de mercado, que repercute negativamente en la asignación de recursos y en el crecimiento económico a mediano y largo plazo. A esto hay que sumarle que los gobiernos encabezando a los Estados pueden estar inmersos en dinámicas de corrupción que llevan a que los funcionarios realicen acciones orientadas solo a su beneficio personal.

El Consenso de Washington es, entonces, un manifiesto de acuerdo con el nivel de instituciones dependientes de Washington sobre las medidas, acciones y políticas económicas que deben llevar a cabo los países en desarrollo para alcanzar condiciones mejores de bienestar. Para ello, plantea un paquete de diez puntos que se deben tener en cuenta en materia de macroeconomía, inversión y economía doméstica.

\subsubsection{Teorías de desarrollo alternativo - humano}

Estas siguen considerándose teorías enmarcadas dentro de los preceptos del desarrollo, aunque presentan novedosos aportes que en algunos casos representan rupturas en relación con la teorización convencional en la materia.

En primer lugar, Max-Neef (1986) introduce el término de invisibilidad para referirse al fenómeno por el cual un gran grupo de individuos (generalmente los más pobres) es velado por otro grupo (los poderosos), al que la historia reconoce equívocamente como protagonista del progreso. 
Para Max-Neef, los verdaderos protagonistas son esos invisibles que día a día, en su silencioso trasegar, construyen la economía y las relaciones sociales en una nación. Conceptos como el del PIB no logran captar la dinámica real tras ese velo que les hace ocultos, y la economía no logra introducir a sus análisis y acciones, las actividades y sectores que usualmente han venido siendo irrelevantes, pero que, muy seguramente, de incluirse, significarían un cambio positivo en la vida de las personas.

En Desarrollo a Escala Humana (1993), Max-Neef señala que el desarrollo es cuestión de personas y no de objetos. Así, la economía y el desarrollo deben estar para mejorar la calidad de vida de las personas. Por ello, el desarrollo debe poner el interés en identificar las necesidades humanas en diferentes niveles y buscar su satisfacción, como una forma de autorrealización de los individuos o de las comunidades.

De esta forma, el autor formula una matriz de necesidades y satisfactores. Estos últimos son los medios para lograr satisfacer las necesidades, y pueden tomar diferente forma de acuerdo con el momento y el contexto. Las necesidades humanas fundamentales se presentan en cuatro categorías ontológicas (ser, tener, estar y hacer) y en nueve categorías axiológicas (subsistencia, protección, afecto, entendimiento, participación, ocio, creación, identidad y libertad). En los cruces entre las categorías ontológicas y axiológicas se establecen los satisfactores que son necesarios. Así, para Max-Neef, el desarrollo se juega con el fin último de satisfacer estas necesidades por el bienestar de las personas.

Por otro lado, Amartya Sen realizó aportes que cambiaron radicalmente el panorama de los estudios del desarrollo en décadas anteriores. El punto de foco es la ampliación de las capacidades humanas, que garantiza un mayor acceso a oportunidades y disfrute de libertades. Según Sen:

(...) la evaluación del desarrollo no puede estar divorciada de la vida que la gente tiene y la libertad real que ellos disfrutan (...) su valor debe depender de los efectos sobre sus vidas y sobre la libertad de las personas inmiscuidas. Para seres humanos responsables, el punto importante debe ser si tienen libertad para hacer lo que piensan que tiene valor. (Sen, 2002, p. 510$)$.

Un sujeto que no tiene posibilidades de elección y libertad de participación en la construcción de un lazo social difícilmente podrá ser visualizado en el marco del desarrollo. Para Sen, "las libertades son tanto objetivo primario del desarrollo como su principal medio" (Sen, 2002, p. 510). Los tipos y grados de libertad para los sujetos de una determinada sociedad deben decir sobre su estado de desarrollo y su posibilidad de alcanzar mejores niveles de bienestar. No hay una libertad, sino varias, y el acceso de las personas a diferentes oportunidades de índole económica, política, social e institucional demarca la existencia para ella de un conjunto de libertades que pueden entrar en interrelación para generar nuevas, y en esa acción está implícita la posibilidad de elección. 
Sen (2000) busca ubicar las garantías apropiadas para el desarrollo humano en el marco de la democracia e intenta derrumbar un mito establecido de manera general, según el cual hay un peso mayor de los derechos económicos y las necesidades materiales sobre las libertades políticas de las personas. Al respecto, señala:

Las verdaderas cuestiones que hay que abordar se encuentran en otro lugar e implican prestar atención a las extensas conexiones que existen entre las libertades políticas y la comprensión y la satisfacción de las necesidades económicas (...) Nuestra conceptualización de las necesidades económicas depende fundamentalmente de las discusiones y [de los] debates públicos abiertos, cuya garantía requiere la insistencia en las libertades políticas y en los derechos humanos básicos. (Sen, 2000).

El ejercicio de las libertades políticas, propio del funcionamiento de un régimen democrático, permite la definición, la delimitación de los "derechos y de las necesidades económicos" para buscar su satisfacción por parte de las instituciones y del colectivo social. Hay, entonces, una relación de circularidad entre los derechos económicos y las libertades políticas, y puede establecerse una relación más general entre el crecimiento económico y las capacidades en el desarrollo humano. Así, satisfacer necesidades económicas aumenta las posibilidades de participación en espacios de ejercicio de las libertades políticas y, a su vez, esta participación en la esfera del debate público mejora las condiciones para conceptualizar, determinar y emprender acciones para la resolución de estas carencias económicas. El asunto de fondo no es el peso mayor de unas libertades respecto de otras, sino la causalidad. Sen, al respecto, dice: "No solo debemos observar las conexiones estadísticas, sino que tenemos que examinar y estudiar los procesos causales que intervienen en el crecimiento y el desarrollo económicos” (Sen, 2000).

\subsubsection{Teorías alternativas al desarrollo}

El posdesarrollo busca desvirtuar la pertinencia del concepto desarrollo. Si a partir de la escuela de la modernización se intentaba validar unas ideas sobre desarrollo de manera universal, para todas las sociedades y comunidades en el mundo, la teoría del posdesarrollo busca, mediante un análisis histórico, entender las maneras como estas categorías fueron construidas como discursos, para poder deconstruirlos y así lograr la relativización de saberes y formas de colectividades humanas.

Un asunto que es relevante en esta escuela es el del discurso. El posdesarrollo busca entender cómo estos eventos históricos, mediante los cuales surge el concepto de desarrollo, se articulan como un discurso que opera en un territorio con efectos adversos para quienes, a partir de ese momento, no tuvieron otra opción que ubicarse del lado de los "subdesarrollados", alcanzando efectos particulares en el ordenamiento global. Al respecto, Gustavo Esteva afirma:

El subdesarrollo comenzó, por tanto, el 20 de enero de 1949 (discurso de Truman). Ese día, dos mil millones de personas se volvieron subdesarrolladas. En realidad, desde entonces 
dejaron de ser lo que eran, en toda su diversidad, y se convirtieron en un espejo invertido de la realidad de los otros: un espejo que los desprecia y los envía al final de la cola, un espejo que reduce la definición de su identidad, la de una mayoría heterogénea y diversa, a los términos de una minoría pequeña y homogeneizante. (Esteva, 1996, p. 52).

Arturo Escobar (2005, p. 18) señala el interés de la corriente posestructuralista como marco determinante de la noción de posdesarrollo. Así, la preocupación real de los teóricos de estos enfoques es indagar por la manera en que el "tercer mundo" obtuvo ese estatus como una "invención" del norte. Esta es una etiqueta de gran peso que han debido cargar los "subdesarrollados", con consecuencias desastrosas para su devenir frecuentemente expresadas como acciones de exclusión, efecto contrario al que se le supuso en el momento de su instauración. El autor señala:

El análisis posestructuralista destacó las formas de exclusión que conllevaba el proyecto de desarrollo, en particular la exclusión de los conocimientos, las voces y las preocupaciones de aquellos quienes, paradójicamente, deberían beneficiarse del desarrollo: los pobres de Asia, África y Latinoamérica. (Escobar, 2005, p. 19).

He señalado dos aspectos que considero claves para definir el posdesarrollo. Por un lado, su estructura de discurso que habla de otros discursos. Por otro lado, el rol principal de las construcciones de la comunidad y la gente del común en el establecimiento de fórmulas que les hagan agentes en su destino. Además, su atemporalidad. No se trata de que el posdesarrollo sea un periodo cronológico presente o que se está viviendo una era del posdesarrollo, sino que se debe entender este como una reacción lógica al desarrollo y sus formas de intervención. Según Escobar, en necesaria "una concientización de que la realidad puede definirse en términos distintos a los del desarrollo y que, por consiguiente, las personas y los grupos sociales pueden actuar sobre la base de esas diferentes definiciones" (Escobar, 2005, p. 22). Sin embargo, el posdesarrollo sí plantea un "después del desarrollo" y un "después del tercer mundo", pero solo en el marco de los imaginarios de los movimientos sociales, es decir, como motivación para el cambio.

\section{Contexto sociopolítico}

Entender las condiciones en que los actores llegaron a sus respectivos periodos presidenciales es crucial para contextualizar las interpretaciones de sus producciones discursivas. Estas condiciones de contexto pueden servir como insumos para la construcción de sus estrategias discursivas, ya que una lectura de este entorno y de las percepciones de opinión pública puede brindar elementos importantes para la producción de discursos y planes de gobierno.

Durante el último intervalo del periodo presidencial de Andrés Pastrana (1998-2002), se presentó una intensificación de las preocupaciones nacionales por el tema de la seguridad. La seguridad se constituyó como un problema de opinión pública que tuvo sustento 
en hechos nacionales, como el fracaso de las negociaciones del Gobierno Pastrana con las FARC, y otros internacionales, como los actos terroristas de 2001 en las Torres Gemelas en Nueva York.

Vargas (2004) describe de manera sistemática los puntos centrales del contexto de la sociedad colombiana en el que se estableció la candidatura de Álvaro Uribe Vélez correspondiente al periodo 2002-2006. Según el autor, este entorno puede dar luces sobre la manera como Uribe, siendo un candidato outsider, con poco reconocimiento nacional y sin muchas posibilidades de éxito y triunfo, logró posicionarse cada vez mejor en las encuestas de intención de voto y ganar en la primera vuelta. Los puntos señalados por Vargas son los siguientes:

- La ruptura del proceso de conversaciones entre el Gobierno del presidente Pastrana y la guerrilla de las FARC. Esta situación se dio en una dinámica de desgaste entre las partes, más que en el marco del establecimiento de negociaciones claras. Asociado con esto, se incrementaron los señalamientos por parte de la opinión pública sobre el uso estratégico de la zona de distensión por parte de la guerrilla con intenciones de fortalecer su accionar terrorista. Lo anterior instituyó un mito sobre la necesidad de una victoria militar del Estado sobre la guerrilla. Según Vargas, se estableció un tránsito en la opinión pública, desde una ilusión por la paz, hacia una ilusión por la guerra.

- La pérdida de credibilidad en la política del momento y en los políticos. Se estableció un fuerte cuestionamiento por el accionar de los partidos políticos tradicionales (Liberal y Conservador) sobre temas como corrupción y clientelismo.

- El estado de crisis económica del país, que presentaba estancamiento en el crecimiento económico.

- La dramática situación social. Según Vargas, se presentó un retroceso de cerca de quince años en los indicadores sociales.

- En el contexto internacional, se fijó una agenda de lucha contra el terrorismo, abanderada por Estados Unidos a raíz de los actos terroristas del 11 de septiembre de 2001. Esta agenda terminó globalizándose.

- El crecimiento de posturas y conductas de autoritarismo en algunos sectores de la sociedad, que se evidenciaron en expresiones de contrainsurgencia no estatal a nivel local.

Gonzáles (2006) también presenta un análisis de la aparición de Álvaro Uribe Vélez en la campaña presidencial de 2002. Según el autor, Uribe se presentó como un candidato independiente de los partidos tradicionales que supo capitalizar los sentimientos populares de inseguridad y el rechazo social a la corrupción política. Muy rápidamente 
creció en las encuestas de intención de voto desde $1 \%$ hasta $50 \%$ frente a los candidatos Horacio Serpa y Luis Eduardo Garzón. De esta forma, se mostró como una alternativa a la forma de política cada vez más carente de legitimidad que, para la gente, había originado las condiciones de intensificación y degradación del conflicto armado.

Uribe se presentó, entonces, como un candidato de postura firme que mostró discursivamente, mediante sus propuestas de gobierno y presentaciones públicas, que podría responder efectivamente a esos sentires populares, para dar el giro requerido a la realidad nacional. De esta manera, su lema de campaña "Mano firme, corazón grande" estuvo acompañado de una propuesta de gobierno basada en una guerra directa contra aquellos actores armados que se resistían a negociar bajo las condiciones establecidas por el Estado. Esta propuesta se plasma en la Política de Seguridad Democrática, que forma parte fundamental del Plan Nacional de Desarrollo (2002-2006) "Hacia un Estado comunitario".

La Política de Seguridad Democrática planteó la necesidad de brindar protección a todos los sectores de la sociedad, recuperar el control de zonas con influencia de grupos armados ilegales, consolidar la presencia estatal en todo el territorio y fortalecer las fuerzas armadas, para lograr el desarrollo social, la confianza inversionista, la recuperación de la economía y la tranquilidad de los colombianos.

Para poder gobernar bajo estos preceptos, Uribe requirió realizar una serie de reformas constitucionales que iniciaron con la declaración del Estado de conmoción interior y el Estado de excepción. Esta condición le permitía al presidente asumir funciones legislativas y tomar medidas especiales para afrontar el tema del orden público, además de asignar mayor presupuesto a las fuerzas armadas.

Según Vargas (2004), los principales retos que se presentaron para el primer periodo de Gobierno del expresidente Uribe fueron los siguientes: 1) lograr avanzar en la superación de la guerra interna, o amenaza terrorista, de la mano de la recuperación de la legitimidad de la fuerza pública y las instituciones; 2) realizar una reforma política dirigida al fortalecimiento del Estado; 3) establecer una política internacional coherente con el discurso del antiterrorismo hegemónico y 4) establecer una política económica que enviara un mensaje de estabilidad y confianza para la generación de empleo. Sobre estos ejes se desarrollaron las acciones de gobierno, que estuvieron siempre respaldadas por una fuerte incidencia sobre la opinión pública y le significaron al expresidente niveles de aceptación popular de hasta un 70 \% en encuestas de percepción de imagen.

Posteriormente, aunque al final del primer periodo presidencial, se acumulaban fuertes golpes a las estructuras de las guerrillas, pero estos grupos aún continuaban operando y adaptándose a las nuevas dinámicas del conflicto armado. Además, Uribe contaba ya con el proceso adelantado de desmovilización de las Autodefensas Unidas de Colombia 
(AUC), que fue objeto de críticas por parte de organismos de derechos humanos, pero que le representó un impacto positivo en términos de opinión pública. En el plano internacional, el presidente George W. Bush había adelantado su campaña reeleccionista en Estados Unidos en 2004, enarbolando la bandera de la lucha antiterrorista, y fue posesionado nuevamente como presidente en 2005. Así, esa sensación de tarea inconclusa, su imagen positiva ante la opinión pública y las señales motivadoras del contexto llevaron a Uribe a aspirar a un segundo periodo de gobierno, defendiendo la idea de la necesidad de consolidar la Política de Seguridad Democrática para el bienestar de los colombianos.

Para poder alcanzar estas aspiraciones, el presidente Uribe requeriría de una nueva reforma constitucional que le permitiera concretar las posibilidades legales para optar por la reelección inmediata. Esta reforma constitucional, aprobada en 2004, desató una fuerte controversia por los polémicos hechos que la rodearon. En ese instante se denunciaron compras de votos en el Congreso para lograr la aprobación de la reforma, y el caso más relevante fue el de la "Yidispolítica", acuñado por la presunta conducta de cambio drástico de posición de voto de la representante a la Cámara, Yidis Medina, a cambio de dádivas. Al respecto, Jaramillo (2005) realiza una revisión histórica y jurídica de los elementos que decantaron en esta reforma constitucional y los pone en relación con el contexto latinoamericano.

Después de una campaña atípica como candidato-presidente, Álvaro Uribe ganó las elecciones presidenciales de 2006 con una amplia votación (7 397835 votos) frente a los candidatos Carlos Gaviria y Horacio Serpa, obteniendo cerca de 2 millones de votos más que en su anterior campaña presidencial. A partir de allí, se dio inicio a la ejecución del Plan Nacional de Desarrollo: "El Estado comunitario, desarrollo para todos" 20062010, que discursivamente establece una continuidad respecto de su anterior plan.

En este contexto se dio la aparición de Juan Manuel Santos como ministro de Defensa Nacional en el nuevo Gobierno de Álvaro Uribe Vélez. En julio de 2006 fue nombrado en este cargo ministerial y solo lo abandonaría hasta mayo de 2009, con claras aspiraciones de emprender una campaña presidencial. Durante su periodo en la cartera de Defensa, la fuerza pública adelantó los operativos militares más contundentes contra las FARG registrados hasta la fecha. Estos incluyen la muerte de altos cabecillas, como alias "El Negro Acacio", alias "Martín Caballero" y alias "Raúl Reyes", la desmovilización de un número importante de integrantes de esta guerrilla, incluidos algunos miembros con mando medio-alto, y la ejecución de la "Operación Jaque", con la se logró la liberación de Ingrid Betancourt, de tres militares estadounidenses y de un grupo de militares que estuvo en poder de la guerrilla por cerca de diez años.

El expresidente Uribe aspiró a una segunda reelección presidencial. En el año 2009, la bancada uribista recaudó cerca de 4 millones de firmas para impulsar un referendo que 
le diera la oportunidad a Álvaro Uribe para continuar en un tercer mandato presidencial. Esta iniciativa tuvo aprobación por el Congreso de la República hacia finales del año, pero, posteriormente, la Corte Constitucional frenó esta iniciativa en febrero de 2010, argumentando vicios de forma.

Ante esta dificultad, sumada a la presión internacional por garantizar dinámicas más democráticas en el país, Uribe tuvo que resignarse a renunciar a sus aspiraciones y dedicarse a encontrar un sucesor que pudiera recibir el legado de sus tesis políticas y la responsabilidad de continuarlas. Entre los posibles candidatos a respaldar se encontraban Andrés Felipe Arias, quien se desempeñó como ministro de Agricultura durante su segundo periodo presidencial hasta 2009; Juan Manuel Santos, quien fue su ministro de Defensa durante su segundo periodo presidencial hasta 2009; y Luis Carlos Restrepo, quien fue el Comisionado de Paz entre los años 2002 y 2009.

Andrés Felipe Arias decidió enfrentarse a Noemí Sanín en la consulta del Partido Conservador para definir candidato único del partido en las elecciones presidenciales. Sin embargo, perdió esta consulta. Luis Carlos Restrepo, por su parte, no mostró una postura lo suficientemente carismática y finalmente pasó a ocupar el cargo de presidente del Partido de la U. De esta manera, el guiño final fue dirigido a Juan Manuel Santos.

Así, con el respaldo del entonces presidente Uribe, Juan Manuel Santos inició su campaña en medio de denuncias públicas por intervenciones de uno a favor del otro. Pero, además de este importante respaldo, Santos requería establecer alianzas que sirvieran de apoyo adicional para garantizar su triunfo en la contienda electoral y que, adicionalmente, sirviera como un terreno firme para su posible gobierno. Al respecto, Clavijo y Morera (2010) señalan:

Juan Manuel Santos, desde el principio de su candidatura, intentó crear una alianza multipartidista alrededor de su proyecto político denominado 'Proyecto de Unidad Nacional'. Alianza que logró materializar con los apoyos que gestionó y fue recibiendo del Partido Conservador, el Partido Liberal y Cambio Radical. (Clavijo y Morera, 2010).

Juan Manuel Santos obtuvo el triunfo en las elecciones presidenciales del año 2010 luego de enfrentarse en primera vuelta con Antanas Mokus, Germán Vargas Lleras, Gustavo Petro, Noemí Sanín y Rafael Pardo, y después de enfrentarse en segunda vuelta con Antanas Mokus. Santos ganó en esta segunda vuelta con la mayor votación de la historia de la democracia colombiana. Según la Registraduría Nacional, esto es 9028 943 votos, un 69,1\% del total de los sufragios.

El contexto en el que Santos asumió el mandato presidencial estuvo marcado por fluctuaciones en los avances de crecimiento económico y fuertes críticas de organizaciones defensoras de derechos humanos a la ejecución de la Política de Seguridad Democrática de su antecesor, Álvaro Uribe. Entre 2003 y 2007, el crecimiento económico inició un 
ciclo de expansión favorecido por la dinámica de economía mundial y el crecimiento de la confianza inversionista, producto de la ejecución de la Política de Seguridad Democrática. En el año 2008, el crecimiento entró en una recesión que se extendió hasta 2009 (Buitrago, 2013). También se registró durante este periodo un aumento de las exportaciones y de la actividad del turismo, así como de la movilidad interna y sensación de seguridad de la población. Por otro lado, según cifras del DANE, hacia 2008 Colombia presentó los más altos índices de desigualdad de la región, medida por el coeficiente de Gini $(0,59)$, y uno de los más altos del mundo, además de una relativa desaceleración de generación de desplazamientos forzados, que tuvo su pico más alto durante el primer periodo presidencial de Álvaro Uribe.

Adicionalmente, Santos comenzó su gobierno con unas fuerzas armadas visiblemente fortalecidas y, sumado a esto, con la ausencia de las Autodefensas Unidas de Colombia - AUC, pero en su lugar surgieron grupos posdesmovilización llamados BACRIM. También existían fuertes críticas a acciones militares como los "falsos positivos" y fuertes señalamientos al Gobierno de Uribe por lo que se denominó la "parapolítica". Por otro lado, recibió un contexto tenso de relaciones internacionales con países vecinos como Venezuela y Ecuador, dadas las estrategias de política exterior asumidas por su antecesor, además de las tensas relaciones con el Poder Judicial que se establecieron anteriormente.

De esta forma, Juan Manuel Santos inició su periodo presidencial con la implementación de su plan de gobierno "Prosperidad para todos" 2010-2014, con el que tácitamente se intuyó algún tipo de transición hacia otras formas de proceder político. Se trataba, entonces, de un tránsito desde la Seguridad Democrática hacia la Prosperidad Democrática, desde políticas con énfasis en la seguridad ciudadana, hacia otras con mayor acento en el desarrollo económico. Así, aunque Santos dio continuidad a puntos importantes de la administración Uribe, como la seguridad y la confianza inversionista, estas políticas no obedecieron necesariamente a una fiel continuación de la Seguridad Democrática, y sus políticas han estado más enfocadas a generar crecimiento redistributivo, condiciones para posicionar a Colombia en el grupo de países desarrollados y escenarios propicios para una salida negociada al conflicto armado interno. Este cambio de enfoque de gobierno le ha significado un distanciamiento de su antecesor, quien paulatinamente ha venido ocupando un rol de crítica y oposición cada vez más fuerte.

\section{Antecedentes de investigación}

La revisión de literatura que aquí se hace está presentada en relación a los temas de conflicto - desarrollo - análisis crítico del discurso. Sin duda, hay mucha información al respecto. Sin embargo, lo seleccionado aquí servirá como marco de referencia para identificar puntos en común y elementos diferenciales respecto de estudios existentes. 
Un punto de partida y marco de referencia que merece ser referenciado es el Informe Nacional de Desarrollo Humano para Colombia del año 2003 "El conflicto, callejón con salida", realizado por el Programa de las Naciones Unidas para el Desarrollo (PNUD). Dicho informe está divido en cuatro partes que presentan una interpretación comprensiva sobre el carácter, la dinámica y las expresiones esenciales del conflicto armado en Colombia, con base en la historia y el contexto político que ha incidido en el conflicto. Así mismo, analiza la relación entre conflicto armado y desarrollo humano, enfatiza en los efectos negativos del primero sobre el segundo y explica cómo el desarrollo humano daría solución al conflicto.

De igual manera, en el documento Nuevos enfoques de política regional en América Latina: El caso de Colombia en perspectiva histórica. Tendencias del desarrollo regional en Colombia. Polarización, apertura y conflicto. Separa 6 de 7 (Moncayo, 2002), se busca realizar una caracterización de las tendencias al desarrollo regional en Colombia y la relación de dichas tendencias con los procesos sociales, económicos y políticos que tienen lugar en el país. Así mismo, se señala cómo el cruce con un modelo de desarrollo que busca la inserción en lo internacional y la deconstrucción de las regionalidades y el conflicto armado ha generado resultados negativos y contraproducentes para el país.

En el texto de Sánchez y Díaz (2005), Los efectos del conflicto armado en el desarrollo social colombiano, 1990-2002, se busca avanzar en el análisis de los efectos sociales de la actividad armada ilegal en el país en los últimos años por medio del examen de la evolución de diversos indicadores de actividad armada, condiciones sociales, capital humano y salud. Basados en indicadores tales como estudiantes matriculados, cobertura en salud, mortalidad infantil, entre otros, se evidencia la fuerte incidencia del conflicto en estas variables, que, a su vez, son indicadores para determinar el desarrollo social del país.

En el libro de Mauricio Uribe (2013) La nación vetada: Estado, desarrollo y guerra civil en Colombia, se realiza una investigación doctoral en la que se identifican y presentan los principales mecanismos explicativos de la prolongación de la guerra civil en Colombia y los modelos de desarrollo en los cuales se ha introducido el país. El autor se apoya en una serie de datos y estrategias del institucionalismo histórico y de la economía política del desarrollo para el contexto de Colombia.

Uribe (2013) plantea que las guerras civiles no son independientes del tipo de instituciones alojadas en las estructuras sociales.

El examen de cierta configuración de características presentes en 31 países con guerras civiles de larga duración avala esa afirmación general. La comparación con los países de América Latina en los que largas guerras civiles han terminado revela aspectos particulares de la retroalimentación positiva entre estilo de desarrollo y la guerra colombiana, que han reforzado la prolongación de esta última. (Uribe, 2013). 
Por otro lado, con el interés de evidenciar el análisis crítico del discurso en relación con el conflicto armado, se presentan trabajos en dirección de la representación de los actores armados en los medios de comunicación, la producción de discursos y los usos discursivos de los presidentes en ruedas de prensa.

Un texto que expone los resultados de análisis lingüísticos a medios de comunicación, especialmente en prensa, es el artículo de Neyla Pardo (2005) titulado "Representación de los actores armados en conflicto en la prensa colombiana". Dicho texto presenta el resultado de dos investigaciones sobre cómo está dada la representación de los actores armados en el conflicto en cuatro periódicos del país, y dio como resultado las diversas formas de nominación de los diferentes actores sociales que están relacionadas con la producción de identidad y la subjetividad en el marco del conflicto armado.

De igual manera, encontramos un texto de la misma autora titulado Cómo hacer análisis crítico del discurso. Una perspectiva latinoamericana (Pardo, 2007). En este libro, la autora toma a Colombia como escenario geopolítico que nutre el objeto de su estudio: conflicto armado y narcotráfico en Colombia y los respectivos procesos de pacificación, con base en las noticas de prensa de los periodos presidenciales desde 1997 hasta 2004.

\section{Aspectos metodológicos}

El análisis crítico del discurso se establece como una metodología analítica pertinente para el abordaje de las formaciones discursivas, entendidas estas como elementos fundamentales de la práctica social. Los discursos determinan y transforman la realidad de los individuos y los colectivos, pues legitiman formas de proceder en los diversos contextos de operación del lazo social. Así, un análisis detallado de las relaciones entre texto y contexto es necesario como base para esta investigación.

Esta metodología permite identificar los mecanismos por los cuales se establecen formas desiguales de acceso a la producción y transmisión de los discursos. Van Dijk (1986, citado por Wodak y Meyer, 2003, p. 17) avanza en este sentido y señala:

En vez de centrarse en problemas puramente académicos o teóricos, su punto de partida (del ACD) se encuentra en problemas sociales predominantes, y por ello escoge la perspectiva de quienes más sufren, para analizar de forma crítica a quienes poseen el poder, a los responsables y a los que tienen los medios y la oportunidad de resolver dichos problemas.

Además de la identificación de formas desiguales de ejercicio del poder en el uso social del lenguaje, permite reconocer dinámicas y lógicas de operación de la ideología y la identidad en la conformación y acción de colectivos sociales. Estos tres elementos son recogidos en el nivel de "práctica social" propuesto por Fairclough en su modelo tridimensional (1989). 


\subsection{Construcción del corpus de análisis}

Para esta investigación se tuvieron en cuenta dos discursos por cada presidente, los cuales fueron emitidos durante su periodo de gobierno correspondiente, y que se consideraron relevantes para el tema de investigación. Estos textos se encuentran en el portal web de la Presidencia de la República o en medios de comunicación reconocidos. Solo se tomaron en cuenta textos producidos entre los años 2002 y 2013, en el periodo de gobierno que corresponde para cada presidente. Es necesario aclarar que se buscó que los textos por analizar constituyeran hitos significativos que pudieran dar cuenta de determinantes de un periodo de gobierno, dado que pueden existir variaciones discursivas durante el tiempo. Los textos seleccionados son como sigue a continuación:

Tabla 1. Textos del corpus de análisis

\begin{tabular}{|c|c|}
\hline Actor & Texto \\
\hline \multirow{2}{*}{$\begin{array}{l}\text { Álvaro Uribe } \\
\text { Vélez }\end{array}$} & $\begin{array}{l}\text { - Texto 1. Discurso de posesión (2002) } \\
\text { http://www.eltiempo.com/archivo/documento/MAM-1339914 }\end{array}$ \\
\hline & $\begin{array}{l}\text { - Texto 2. Alocución presidencial - Contra el terrorismo (2003) } \\
\text { http://www.primerocolombia.com/es/content/alocucion-presidencial }\end{array}$ \\
\hline \multirow{2}{*}{$\begin{array}{l}\text { Juan Manuel } \\
\text { Santos }\end{array}$} & $\begin{array}{l}\text { - Texto 1. Discurso de posesión (2010) } \\
\text { http://wsp.presidencia.gov.co/Prensa/2010/Agosto/Paginas/20100807_15.aspx }\end{array}$ \\
\hline & $\begin{array}{l}\text { - Texto 2. Palabras del presidente Juan Manuel Santos en la presentación de los de- } \\
\text { cretos reglamentarios de la Ley de Víctimas y Restitución de Tierras (2011) } \\
\text { http://wsp.presidencia.gov.co/Prensa/2011/Diciembre/Paginas/20111220_06.aspx }\end{array}$ \\
\hline
\end{tabular}

Fuente: Construcción propia a partir de las fuentes para el análisis.

\subsection{Recolección y análisis de datos}

Con base en los planteamientos de Fairclough (1989) sobre su modelo tridimensional de análisis del discurso, Medina (2013) diseñó un esquema de matriz de recolección y análisis de información para su tesis doctoral sobre análisis crítico del discurso y desarrollo sostenible. Esta matriz es usada en la presente investigación y ajustada a los requerimientos propios del estudio, dadas las diferentes categorías planteadas en la investigación, como lo son dos actores diferentes (presidentes), cuatro textos (dos por cada presidente) y dos categorías (conflicto armado y desarrollo).

Según el modelo tridimensional de Fairclough (1989), existen tres niveles de análisis del discurso: el análisis de textos (hablados o escritos), el análisis de la práctica discursiva (procesos de producción, distribución y consumo de los textos) y el análisis de los eventos discursivos como instancias de práctica sociocultural (los contextos sociopolíticos) 
(Faircluogh, 1989). Esto nos lleva a pensar el lenguaje como un producto de la organización lingüística en todos los niveles de análisis: pragmático, conversacional, sociolingüístico y gramatical.

Figura 1. Modelo tridimensional de Fairclough

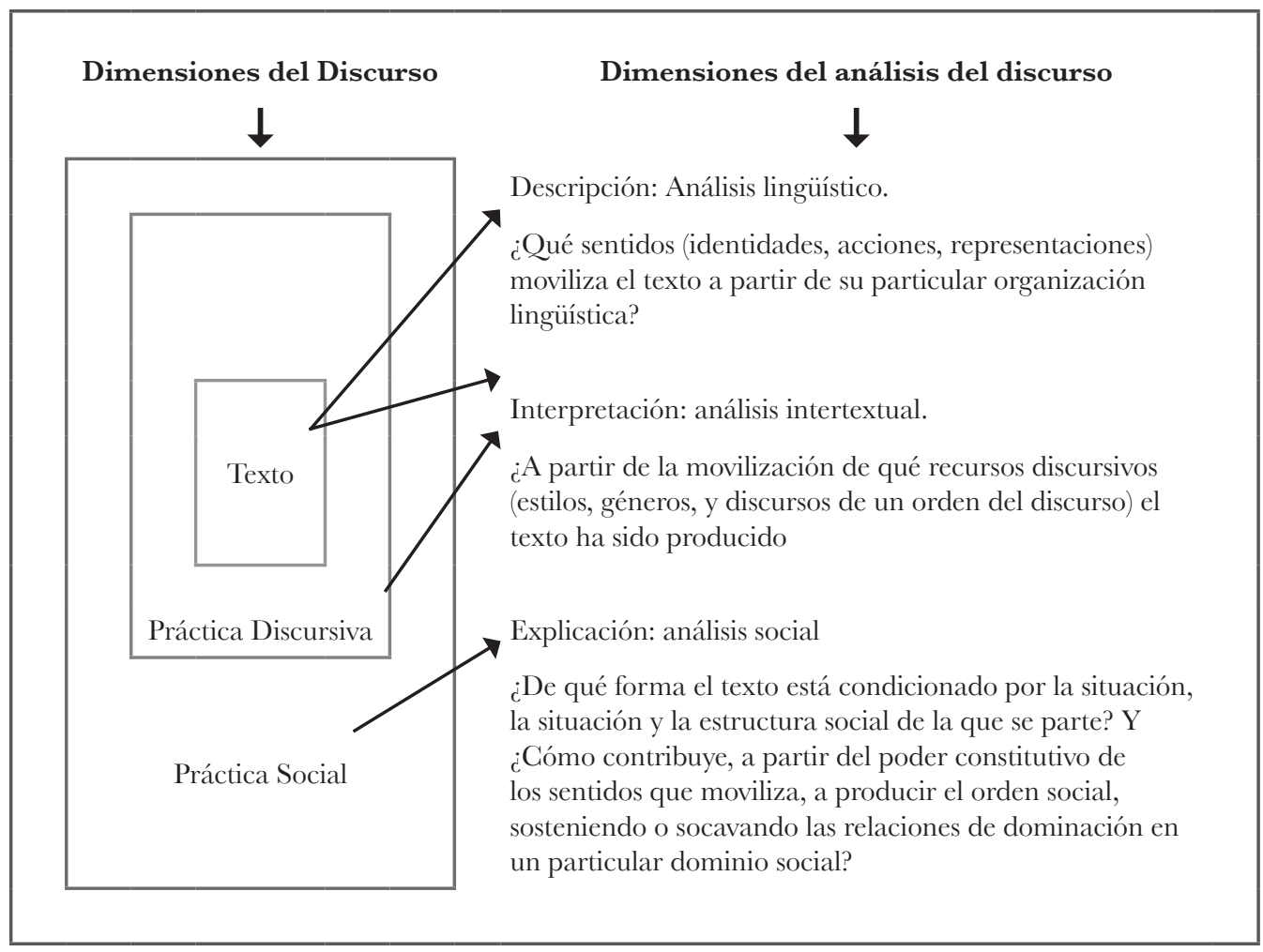

Fuente: Construcción hecha por Stecher, (2009), a partir de la figura elaborada por Fairclough, (1989).

Se trata, entonces, de un análisis que va desde lo textual hasta lo contextual. Parte de lo estrictamente lingüístico y gramatical, pasando por las formas como se produce y consume el discurso en el marco de la operación de las instituciones, hasta llegar a un análisis de las relaciones dialécticas que se establecen en el contexto social mediante la instalación de discursos hegemónicos y la constitución de colectivos cargados de ideología e identidad de grupo (identidad nacional).

La matriz de recolección y análisis de información ajustada a los requerimientos del estudio se aplicó a cada uno de los cuatro textos seleccionados. En ella se consignaron los elementos de manera diferencial entre conflicto armado y desarrollo, esto con el fin de facilitar la utilización de los datos en los posteriores análisis. Sin embargo, es necesario aclarar que, aunque el ejercicio de recolección de información se realizó para las tres dimensiones de análisis, la discusión y los resultados para este estudio se concentran en 
la tercera dimensión de "práctica social", dado el planteamiento de los objetivos específicos de la investigación, enmarcados en esta categoría.

Tabla 2. Formato de matriz de recolección y análisis de datos

\begin{tabular}{|c|c|c|c|}
\hline \multicolumn{4}{|c|}{ Matriz de recolección y análisis } \\
\hline Álvaro Uribe & & Juan Ma & l Santos \\
\hline Conflicto armado & Desarrollo & $\begin{array}{l}\text { Conflicto } \\
\text { armado }\end{array}$ & Desarrollo \\
\hline
\end{tabular}

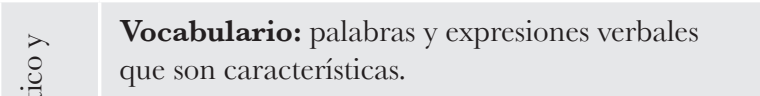

Gramática: formas de expresión que inciden tanto en las relaciones entre los objetos y las entidades como en las relaciones sociales.

Cohesión: cómo se presentan los propios objetivos con ayuda del vocabulario y de sutilezas retóricas.

Estructura: cómo se caracteriza el problema y cómo se combinan los hechos para producir una cierta imagen.

Intertextualidad: influencia de otros textos y desarrollo de nuevas configuraciones.

Interdiscursividad: desarrollo en relación con discursos nuevos y discursos tradicionales.

Coherencia: el texto como totalidad congruente entre la opinión del productor y la del consumidor.

Fuerza y control: tipo de acción que constituye el texto y quien dirige y controla su producción.

Relaciones dialécticas: relaciones de carácter necesario que generan y desarrollan el discurso.

Aspectos ideológicos: aspectos contextuales y elementos discursivos que juntos desencadenan determinadas asociaciones en la interpretación del discurso.

Procesos hegemónicos: luchas entre los actores en relación con el discurso dominante.
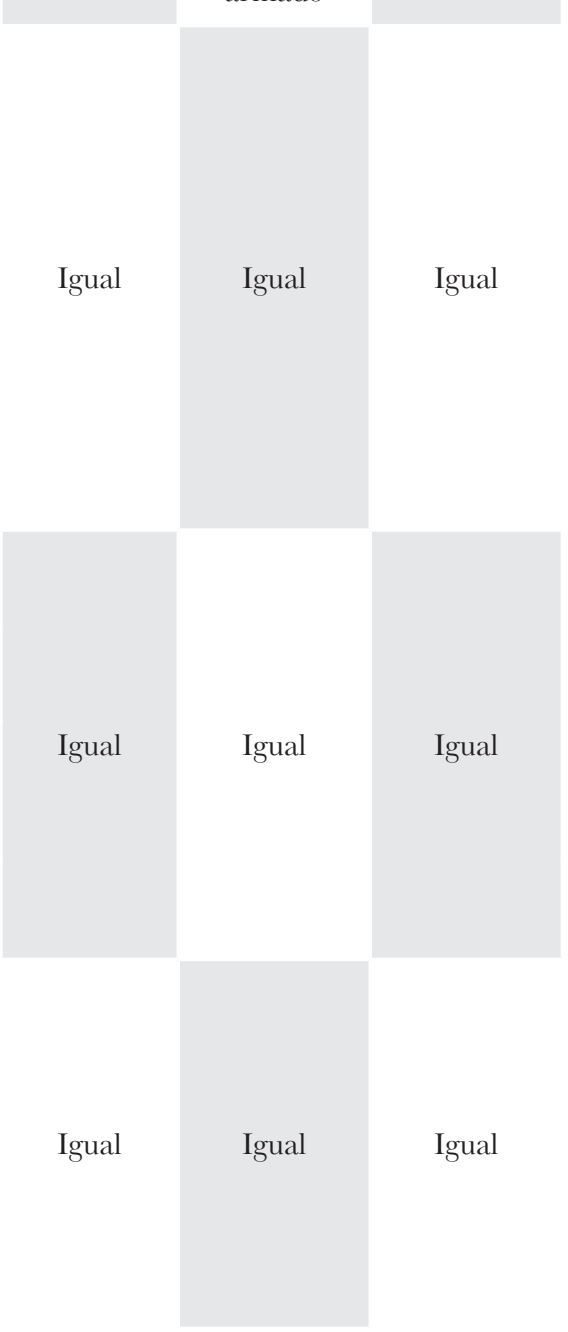


\section{Resultados y discusión}

Se presenta a continuación la información obtenida a partir de la aplicación del modelo diseñado para realizar el análisis crítico del discurso propuesto. Como se mencionó en el anterior apartado, estos resultados se irán poniendo en relación con los objetivos específicos de la presente investigación, a la luz de la dimensión "práctica social", a partir de la cual Fairclough plantea un vínculo entre la acción discursiva y el contexto social en los procesos de producción, transmisión e interpretación de los textos (Fairclough, 1989, p. 26).

Sin embargo, no se desconocen aspectos relevantes relacionados con las otras dimensiones de análisis del modelo tridimensional, dado que los resultados consignados en la dimensión "práctica social" se conectan, a su vez, con información propia de las dimensiones "texto" y "práctica discursiva".

El análisis de los datos obtenidos permite identificar posibles continuidades y discontinuidades entre las ideas fundamentales que constituyen los textos y los discursos de Álvaro Uribe Vélez y Juan Manuel Santos en sus respectivos periodos presidenciales, que dan cuenta de intencionalidades y efectos en las dinámicas sociales y políticas, que para cada caso pueden ser diferentes. Se exponen a continuación los resultados.

\subsection{Identidades nacionales}

Los datos arrojados por este estudio reflejan la importancia de la referencia por parte de los actores a elementos de identidad nacional como mecanismo de sustento y soporte en la producción de sus discursos. Esta construcción discursiva en torno a la identidad nacional sirve como mecanismo de cohesión colectiva para obtener respaldo popular y así justificar, defender y legitimar ideas centrales del discurso y acciones sustentadas en este. Al respecto, Freud (1921), en discusión con Le Bon, hace una clara descripción de la formación de una masa psicológica y sus mecanismos de operación. En primer lugar, los individuos en el interior de una masa están ligados en una unidad. De allí que lo que es verdaderamente relevante es la ligazón que produce esa unidad. Esa unión puede ser, justamente, lo característico de la masa. Los vínculos establecidos deberán generar sentimientos de cercanía afectiva entre quienes conforman la unidad. Esta situación se compone a partir de la identificación con la que "aspira a configurar el yo propio a semejanza del otro, tomado como modelo".

Las formaciones discursivas que se refieren a identidades nacionales pueden tener, adicionalmente, otras intenciones respecto a la misma existencia de esos rasgos de identificación colectiva y su respectiva interpretación sociocultural. Según Wodak y Meyer (2003), hay cuatro estrategias discursivas en la producción de textos sobre las naciones y las identidades nacionales: estrategias constructivas (construir identidad), estrategias de 
preservación o justificación (conservar las identidades existentes), estrategias de transformación (alteraciones de las identidades existentes), estrategias de destrucción (desmantelamiento de las identidades existentes). La producción narrativa de los actores se desarrolla en el marco de estas cuatro estrategias discursivas y, de acuerdo con el contexto, tales estrategias se usan también para instalar otro tipo de formaciones tanto discursivas como hegemónicas.

Revisados los dos textos pronunciados por cada presidente, se encontró que para cada actor existen elementos conglomerantes diferenciales de identidad nacional que soportan sus discursos. Algunos de esos elementos se mantienen en el tiempo durante uno o varios periodos presidenciales, otros se corresponden en algún momento entre actores y otros más son completamente nuevos e inéditos en la producción discursiva. Así, en los discursos se establecen, de manera implícita y explícita, preguntas del tipo ¿qué somos?, ¿quiénes somos nosotros los colombianos?, ¿quiénes quedan fuera del nosotros y por qué?, ¿cuál es la naturaleza de ser colombianos? y ¿cuáles deben ser los valores de una nación?, entre otras.

Estos datos permiten encontrar un punto en común entre los dos textos del presidente Uribe. Para ambos discursos, la solicitud de subordinarse al orden de la autoridad, ya fuera mediante la obediencia o el servicio (informar), es un imperativo. Estos son mecanismos de poder que se instalan como discursos hegemónicos con el fin de realizar transformaciones en las lógicas de dinámica social.

En relación con el texto 1 de Uribe, este poder pleno debe estar impulsado por el apoyo popular manifiesto en torno a elementos como ley, norma, orden, autoridad. De esta forma, lo que se busca es obtener la legitimidad del uso y operación de la autoridad. Esta legitimidad, a su vez, sirve de base para la producción de un discurso hegemónico sobre el uso firme de la seguridad con fines de protección ciudadana: "Seguridad Democrática".

Por otro lado, el actor busca generar una toma de posición por parte de la población mediante la alusión a elementos identificativos que cohesionen, constituyan grupo y determinen ideologías. Pero estos mecanismos colectivos se activan por medio de procesos de cognición social. Según Van Dijk (2003), las representaciones sociales se expresan por medio de modelos mentales. Al respecto, señala:

(...) su expresión en los textos y en las conversaciones se realiza por medio de modelos mentales. Y a la inversa, si adquirimos nuestro conocimiento del mundo, nuestras actitudes socialmente compartidas y, por último, nuestras ideologías y nuestras normas y valores fundamentales, se debe a que lo hacemos a través de modelos mentales del discurso cotidiano, como el de las conversaciones, las noticias de los reportajes y los libros de texto. (p. 168).

De esta forma, hay una afectación en doble vía entre los textos y las producciones discursivas, y los modelos mentales. Estos últimos pueden definir formaciones discursivas; 
a su vez, los textos pueden determinar formaciones de modelos mentales. La identidad nacional, como conocimiento cultural, es compartida por los miembros de una sociedad o una nación y puede determinar también actitudes entendidas como "opiniones que la gente tiene sobre determinado tema" (Van Dijk, 2003, p. 169).

Según el actor, en la referencia en el primer texto al "decaimiento del capital social", se descarta completamente la posibilidad de que esta radique en la "naturaleza" de ser colombianos, otorgando a la población unas características positivas y señalando el origen de esta condición en la "violencia destructora". Esta formación discursiva descarta también de tajo la posibilidad de que la violencia en el país encuentre causales en la "naturaleza" de ser colombiano, es decir, en los factores socioculturales. Por ello se evidencia una lógica de manipulación de las formaciones discursivas para alcanzar objetivos ideológicos específicos.

En relación con el segundo texto de Uribe, el actor llama a la Unidad Nacional contra la violencia y el terrorismo y, de esta manera, se establece un enemigo único al cual derrotar por medio de acciones claves como informar, cooperar y colaborar. Así se configuran las redes de informantes y cooperantes y los sistemas de recompensas. Se da de esta manera la instalación de un discurso hegemónico, en el cual estas acciones son deberes del ciudadano y valores de la sociedad colombiana.

Tabla 3. Unidades discursivas relevantes - Álvaro Uribe - Identidad nacional

\begin{tabular}{|c|c|}
\hline \multirow{9}{*}{ 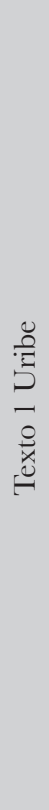 } & $\begin{array}{l}\text { "Retomemos el lazo unificador de la ley, la autoridad democrática, la libertad y la justicia social, } \\
\text { extraviado en momentos desapacibles de la historia". }\end{array}$ \\
\hline & "Para el reposo del Libertador, recuperemos el orden...". \\
\hline & $\begin{array}{l}\text { "...orden, que unifique esta Nueva Granada disgregada hoy en repúblicas de facto de organizaciones } \\
\text { violentas". }\end{array}$ \\
\hline & "Bolívar entendió el orden como principio de unidad y de justicia social". \\
\hline & "Bolivar y Santander prefiguran nuestra identidad política como nación". \\
\hline & $\begin{array}{l}\text { "Que el hombre de las leyes nos inspire una Nación de obediencia a las normas para cancelar la esclavitud de } \\
\text { la violencia" }\end{array}$ \\
\hline & (Santander) "Honró la ley con su obediencia a la autoridad...". \\
\hline & “...convoco a los colombianos y colombianas a retomar el lazo unificador de la ley". \\
\hline & $\begin{array}{l}\text { “...un decaimiento del capital social... no surge de la naturaleza de ser colombiano, que es cívica y } \\
\text { humanitaria...su razón de ser la explica la violencia destructora...". }\end{array}$ \\
\hline
\end{tabular}


Análisis crítico del discurso sobre conflicto armado y desarrollo en los presidentes...

Carlos Pabón

“(..) lo que tiene que ser Colombia: 44 millones rodeando las instituciones para derrotar a la delincuencia".

"Hay que informar por solidaridad, porque todos somos responsables de nuestra sociedad".

"Si todos ayudamos, la Fuerza Pública podrá desbaratar los planes de los terroristas".

Fuente: Construcción propia a partir de los textos del corpus de análisis.

Por su parte, Juan Manuel Santos busca construir unidad a partir de la construcción de identidad. Inicialmente lo hace mediante la alusión a elementos de una herencia colombiana en las culturas indígenas de la Sierra Nevada de Santa Marta y posteriormente resaltando otras raíces, como la española y la africana, a partir de las cuales se construye "lo que somos". Este uso de elementos de identidad le permite formular la idea de diversidad como posibilidad de unidad: "Unidad dentro de la diversidad".

La alusión a otros elementos de identidad, como la historia de la independencia y los próceres de la patria, permite hacer cohesión en torno a ideas como la libertad y la justicia. La forma de consolidar esta idea es acudiendo a la celebración del Bicentenario de la Independencia de Colombia: "Somos la generación del Bicentenario: una generación con sentido del pasado y con vocación de futuro".

La "Unidad dentro de la diversidad" sirve de base para el postulado sobre la "Unidad Nacional", un llamado a sumarse en un proyecto de gobierno, sin importar pertenencias a grupos sociales, razas, ideologías o a partidos políticos. Al respecto, el actor afirma: "Sobre las diferencias ideológicas se impone el destino compartido de hermanos de historia y de sangre".

Este proyecto de "Unidad Nacional" estaría encarnado por un líder, el presidente Juan Manuel Santos. Al respecto, en el texto 1 de análisis señala: "Soy y seré el presidente de la Unidad Nacional". A partir de allí él establece, como mecanismo de uso del poder, una oposición de categorías de identificación política: la Unidad Nacional (nosotros) y la oposición (otros). Con el establecimiento de un "nosotros" y un "otros" se establece un requerimiento a la población de tomar partido o tomar posición. La pregunta que surge es, entonces, ¿qué implicaciones habría por no ser parte de la Unidad Nacional?

De acuerdo con lo anterior, es importante señalar que con esta legitimación del discurso se buscaría una identificación de la masa con la figura del líder, quien es el emisor, pero, a su vez, portador e impulsor de estas ideas asociadas con los elementos de identidad nacional que cohesionan. En últimas, se busca que, al asociarlas con los elementos de identidad nacional, las ideas centrales del discurso obtengan la misma capacidad de cohesión social y efecto sobre las acciones. Para Freud (1921), la comunidad o masa psicológica tiene sustento en el modo de vínculo con el líder o conductor. "La necesidad 
ISSN: 0124-3551 / Año 17, No 27 / julio-diciembre / pp. 55-102

de la masa solicita un conductor", quien es el portador de una intensa creencia o idea y asume el rol de autoridad, ante el cual se debe obedecer como hipnotizado a su hipnotizador.

Tabla 4. Unidades discursivas relevantes - Juan Manuel Santos - Identidad nacional

"Nuestro país es una maravillosa combinación de culturas, de razas, de talentos, de riquezas naturales, que nos hace únicos en el planeta".

"45 millones de compatriotas que venimos de esa herencia indigena... y de tantas otras vertientes que han construido lo que somos".

"(...) un puñado de neogranadinos dio los primeros pasos en nuestro camino hacia la independencia".

"Somos la generación del Bicentenario: una generación con sentido del pasado y con vocación de futuro".

"(...) siento que nos miran desde la historia nuestros padres, Bolivar, Santander, Nariño y todos los hombres y mujeres que lucharon por darnos la libertad".

"(...) tenemos que construir unidad entre nosotros, los herederos de la gesta libertaria".

"Soy y seré el presidente de la Unidad Nacional".

"Me da pena decirlo, pero los colombianos si hemos sido culpables de algo: de haber sido indiferentes o, por lo menos, de no haber hecho lo suficiente para evitar esta tragedia (la del desplazamiento)".

Fuente: Construcción propia a partir de los textos del corpus de análisis

\subsection{Estructuras de poder y modelos de desarrollo}

Los resultados de este estudio muestran que, en las relaciones sociales establecidas, particularmente la que se dan entre los líderes y la masa, hay búsquedas de ejercicio del poder, relaciones desiguales, asunciones de autoridad, pretensiones de alienación e instalación de discursos hegemónicos. Así, los discursos de los presidentes, desde un lugar de autoridad, introducen textos con los que se busca arraigar ideas sobre el desarrollo y sus fuentes en los receptores nacionales. Con estos discursos se busca legitimar unas lógicas y relaciones de poder que abran posibilidades para la acción en la planeación y ejecución de estrategias de desarrollo. Esto se encuentra en relación con lo planteado por Wodak y Meyer, quienes señalan que “(...) las estructuras dominantes estabilizan las convenciones y las convierten en algo natural, es decir, los efectos del poder y de la ideología, en la producción de sentido quedan oscurecidos y adquieren formas estables y naturales: se los considera como algo 'dado'" (Wodak 
Análisis crítico del discurso sobre conflicto armado y desarrollo en los presidentes...

Carlos Pabón

y Meyer, 2003, p. 20). De esta forma, la mejor manera de establecer convenciones es instalar discursos hegemónicos.

Para el caso de Álvaro Uribe Vélez, el establecimiento de estructuras de poder popularmente legitimadas, que justifican la necesidad de operación de la autoridad y el orden, y que son sustento para la aplicación de la fuerza o cualquier otra acción necesaria para vencer el terrorismo y la violencia son condición necesaria para la instalación del modelo de desarrollo basado en la idea de crecimiento económico como único mecanismo del Estado para obtener ingresos y recursos. Estas estructuras de poder se materializan para el actor en la forma de un Estado garante, en un Estado "promotor del desarrollo, garante de la equidad social y dispensador del orden público", un Estado que debe gozar de aceptación popular, un Estado ejemplarizante, pero, ante todo, un Estado con autoridad asociada con otra estructura de poder que encuentra asiento en una fuerza pública que debe, a su vez, estar rodeada por las instituciones y por la población en general.

Pero estas estructuras de poder, así como establecen formas de relación entre líder gobierno y masa (obediencia, apoyo), también establecen unas formas de lazo social entre los integrantes de la masa nación, diferenciando entre quienes se identifican o no con las fórmulas de elementos cohesionadores. Estos son también ejercicios del poder. Estas dinámicas establecen polarizaciones que son producidas por formaciones discursivas, pero que también originan reediciones de los textos con algunas rupturas y discontinuidades.

Tabla 5. Unidades discursivas relevantes - Álvaro Uribe - Estructuras de poder y desarrollo

“(..) el primero (Bolivar) encarna la idea de orden y autoridad. El orden como presupuesto ineludible de la
libertad, la autoridad que hace posible la igualdad de oportunidades. El segundo (Santander) representa el
imperio de la ley que garantiza la seguridady las libertades".
"(..) un decaimiento del capital social no surge de la naturaleza de ser colombiano, que es cívica y
humanitaria. Su razón de ser la explican la violencia destructora, la politiquería y la corrupción, que concurren
en la incertidumbre, la miseria y la desigualdad”.
"Un pueblo que jamás ha rendido la cabeza, pero que reclama firmeza en el timonel para interrumpir
el triste discurrir de la miseria...".
"El ajuste fiscal para enderezar las finanzas públicas es ineludible, pero se adelantará en procura de un mayor
crecimiento de la economía y el empleo. El crecimiento económico es el mejor ajuste fiscaly la única
fuente perdurable de ingresos del Estado".
"Resulta equivocado considerar que con trabas comerciales dentro de la región alguno de nuestros países
pueda acelerar el crecimiento".


ISSN: 0124-3551 / Año 17, No 27 / julio-diciembre / pp. 55-102

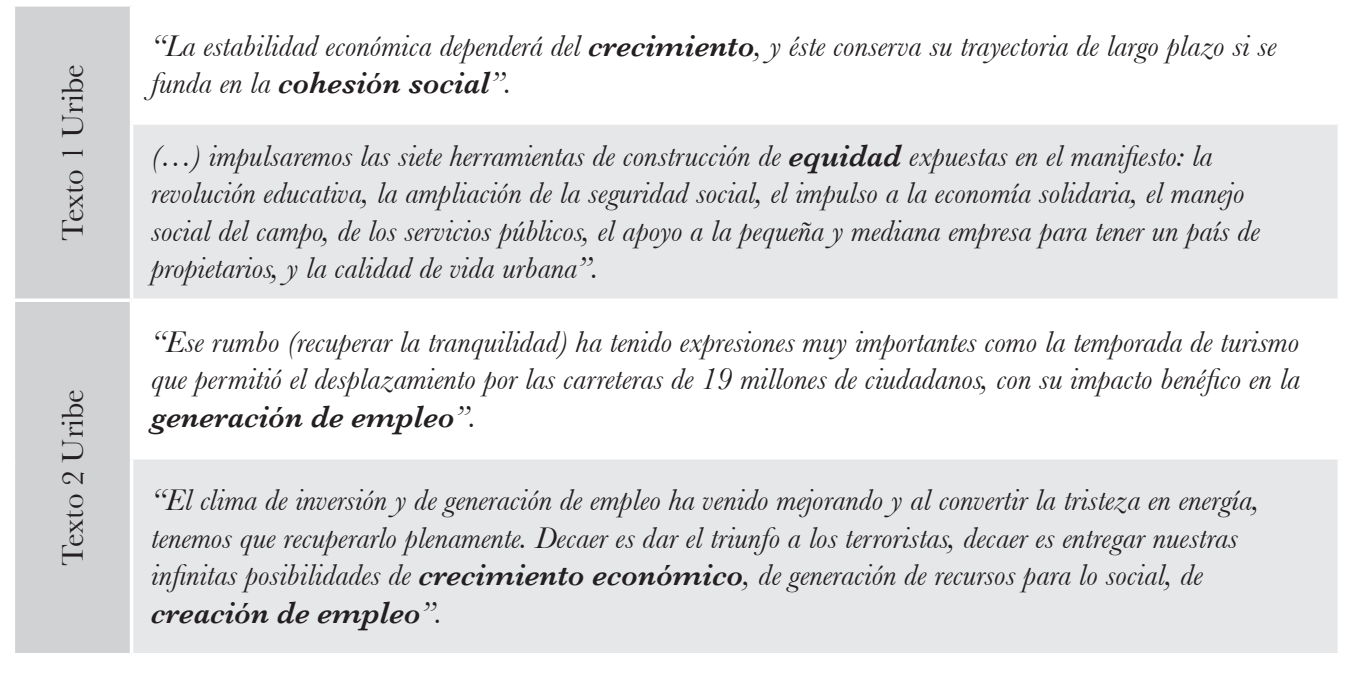

Fuente: Construcción propia a partir de los textos del corpus de análisis.

Para el caso de Santos, la cohesión (Unidad Nacional) por sí sola es condición necesaria y suficiente para avanzar hacia la prosperidad. Santos desprovee a la Unidad Nacional de los elementos de autoridad y orden, y dirige su atención directamente a la prosperidad, soporte y eje transversal de su plan de desarrollo.

Siguiendo la lógica presentada en el texto 1, si la unidad es condición necesaria para la obtención de desarrollo, la Unidad Nacional, como proyecto de político de gobierno, es también una condición necesaria para el desarrollo.

El actor busca instaurar el discurso hegemónico de la "Prosperidad Democrática". Esta política abarca los diferentes postulados de su plan de desarrollo, y se entiende en el texto como una etapa posterior y más avanzada, aunque no desligada, con respecto a la "Seguridad Democrática” de su antecesor, Álvaro Uribe Vélez.

Aunque en algunos apartados de los textos Santos manifiesta su intención de consolidar la "Seguridad Democrática" como expresión de una identificación ideológica con su antecesor y asume la responsabilidad de recibir y dar continuidad a su legado, en algunos otros apartes del texto se hace referencia a la necesidad de que el país dé el paso hacia la "Prosperidad Democrática", y se hace evidente así la necesidad de una ruptura respecto del discurso de su antecesor.

Dentro de las ideas de desarrollo presentadas por Juan Manuel Santos, la libertad es producto de la justicia social y la paz. A diferencia de los planteamientos de Álvaro Uribe, quien afirmaba en su primer discurso presidencial que la libertad es producto de la autoridad y el orden, según Juan Manuel Santos, en el texto 1 de análisis, "el concepto 
de la libertad tiene su razón de ser y su plena expresión si está ligado a la dimensión de la justicia y a la magnitud del bienestar social".

Otra idea que busca establecerse como hegemónica en el texto 2 es la posibilidad de transformar los efectos del conflicto en posibilidades de desarrollo. En esta medida, se trata de oportunidades de desarrollo para quienes han sufrido los embates del conflicto. Transformar efectos de la guerra en posibilidades de desarrollo. Esta condición de resiliencia, entendida como la facultad de los seres humanos para reponerse frente a situaciones adversas (Puerta y Vásquez, 2012), puede ser interpretada como una capacidad de gran importancia en el marco de las concepciones sobre desarrollo humano. Según Sen (2000), el ser humano es agente de desarrollo social y del desarrollo propio, y en la medida en que se eliminen las privaciones de las libertades humanas y aumente la capacidad de elección para el individuo, la resiliencia irá proporcionando mejores posibilidades para la consecución de personas sociales más plenas, por encima de las tragedias vividas en su historia de vida.

Por otro lado, se entiende en el discurso una doble vía de relación entre conflicto y desarrollo. En primer lugar, el establecimiento de medidas de desarrollo para la población víctima como condición necesaria para la superación de los efectos del conflicto y, por otro lado, la necesidad de terminación del conflicto como condición necesaria para la no repetición de eventos victimizantes y acceso a oportunidades reales de desarrollo.

El desarrollo prometido a las víctimas mediante la implementación de la Ley 1448 de 2011 se concreta en indemnizaciones que puedan estar dirigidas a "invertir en su futuro" mediante adquisición de vivienda, acceso a educación o proyectos productivos, también mediante la garantía de recuperar sus tierras o tener acceso a nuevas.

Tabla 6. Unidades discursivas relevantes - Juan Manuel

Santos - Estructuras de poder y desarrollo

\footnotetext{
"Si queremos lograr el pleno desarrollo económico y social, tenemos que construir unidad entre
nosotros".
“(..) una infima minoría que persiste en el terrorismo y el narcotráfico, en obstruir nuestro camino

$\begin{aligned} & \text { hacia la prosperidad". } \\ & \text { "Si este país, en estos dos siglos, ha alcanzado tantos logros de desarrollo en medio del asedio de }\end{aligned}$
"Lucharé por consolidar y acrecentar su inmensa obra de gobierno (la de Uribe)".
"Tal como lo prometí en mi campaña, avanzaremos desde la Seguridad Democrática hacia la Prosperidad
Democrática".
} 
ISSN: 0124-3551 / Año 17, No 27 / julio-diciembre / pp. 55-102

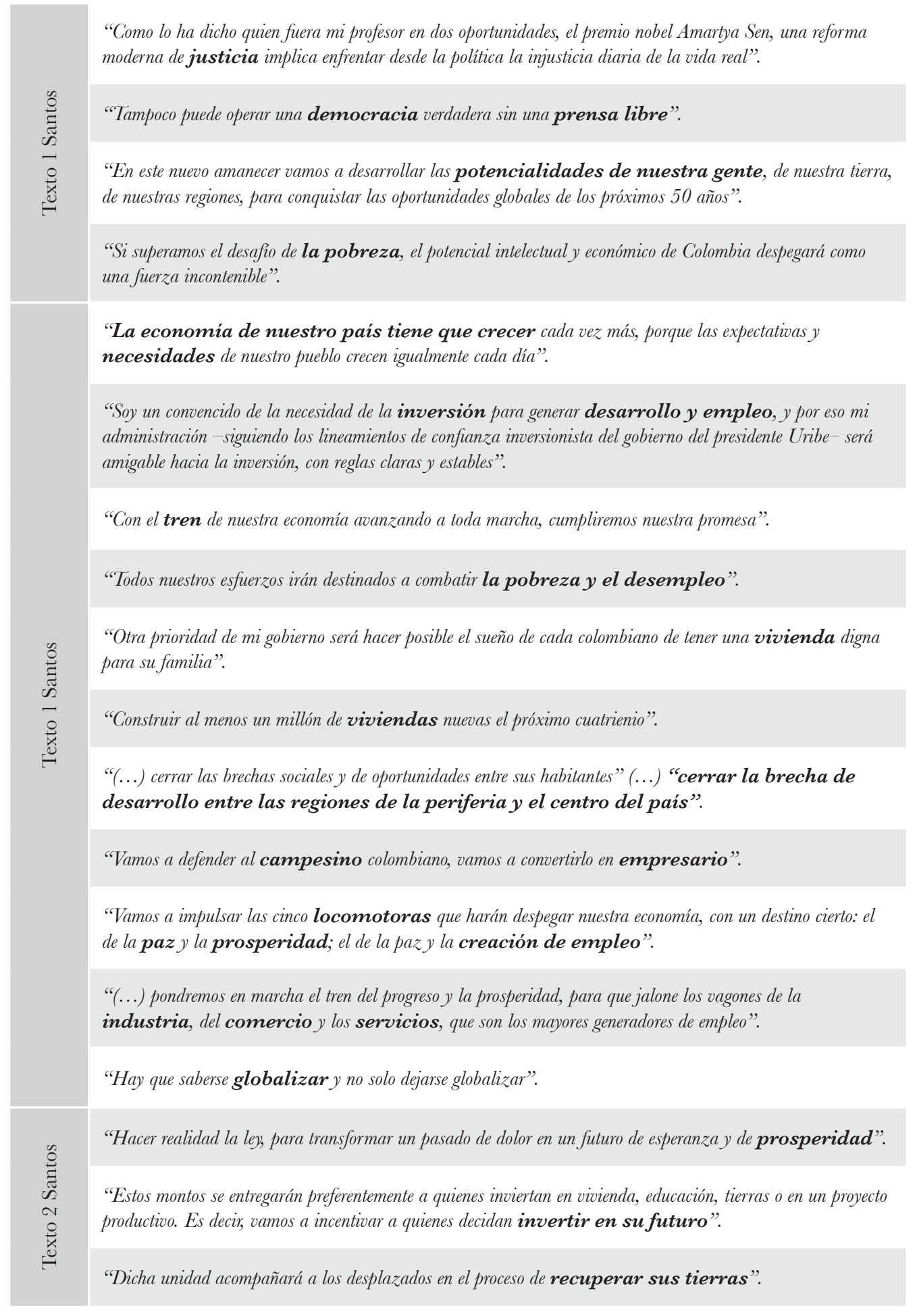


Análisis crítico del discurso sobre conflicto armado y desarrollo en los presidentes...

"Hemos dado pasos firmes antes de comenzar a implementar la Ley, y otro de esos pasos es el recién creado Sector de Prosperidad Social, que considera a las víctimas como sujetos prioritarios de nuestra política contra la pobreza".

"AAsi se construye la paz!, devolviéndoles la tranquilidad a los despojados, permitiéndoles cumplir el anhelo de volver a su hogar".

Fuente: Construcción propia a partir de los textos del corpus de análisis.

\subsection{Sistemas ideológicos sobre conflicto armado y desarrollo}

Van Dijk (2003) define las ideologías como "las representaciones sociales de los grupos sociales". La ideología es, entonces, la identidad del grupo, colectivo o masa. A partir de allí se instituyen los "dispositivos de pertenencia, los objetivos, las actividades, las normas y los recursos de cada grupo. Las ideologías contienen los principios básicos que organizan las actitudes que comparten los miembros de un grupo" (p. 170). Así, las ideologías pueden generar dinámicas de inclusión/exclusión que determinan relaciones desiguales de poder entre los individuos. Con base en la ideología, los individuos son convocados a tomar partido frente a un colectivo y sus principios determinantes.

Los resultados del presente estudio indican la existencia de diferentes enfoques ideológicos en los discursos de los actores. Aunque existen ciertas continuidades discursivas frente al asunto del conflicto armado, existen también grandes rupturas o discontinuidades frente a su tratamiento.

Estos resultados, para el caso de los discursos de Álvaro Uribe Vélez, muestran construcciones que buscan establecer una identidad de grupo-nación en torno a la autoridad y la fuerza, propios de las corrientes políticas de derecha, además de la identificación de la población con una idea de nación activa y combativa contra el enemigo único: el terrorismo. Esta lógica de identidad funciona articulada con el establecimiento de objetivos del grupo: derrotar el terrorismo y recuperar la tranquilidad. El primero como condición necesaria para la obtención del segundo. La fórmula para alcanzar estas metas es vincular a los ciudadanos a las estrategias de combate de los grupos armados ilegales mediante la colaboración, información y cooperación con la fuerza pública, que es la única que puede tener el monopolio legítimo de las armas. Así, ante estos postulados, la población deberá apostarle a una u otra condición, la de estar dentro o fuera del grupo nación propuesto, cada una con efectos y consecuencias distintos.

Por otra parte, no se evidencia ninguna referencia a elementos jurídicos o de ley para argumentar el tratamiento de terrorismo, salvo una solicitud a la comunidad internacional para lograr este reconocimiento de estatus. Sin embargo, este nombramiento sí es usado a nivel discursivo para convocar a la Unidad Nacional para legitimar la política de Seguridad Democrática. 
ISSN: 0124-3551 / Año 17, No 27 / julio-diciembre / pp. 55-102

Tabla 7. Unidades discursivas relevantes - Álvaro Uribe - Ideología y conflicto armado

\begin{tabular}{|c|c|}
\hline & "(Santander)... honró la ley con su obediencia a la autoridad...". \\
\hline$\frac{8}{\square}$ & $\begin{array}{l}\text { "(...) orden, que unifique esta Nueva Granada disgregada hoy en repúblicas de facto de organizaciones } \\
\text { violentas". }\end{array}$ \\
\hline$\stackrel{0}{\stackrel{x}{e}}$ & $\begin{array}{l}\text { "Nuestro concepto de Seguridad Democrática demanda aplicarnos a buscar la protección eficaz } \\
\text { de los ciudadanos con independencia de su credo político o nivel de riqueza". }\end{array}$ \\
\hline
\end{tabular}

"Apoyaré con afecto a las fuerzas armadas de la nación y estimularemos que millones de ciudadanos concurran a asistirlas".

"Cuando un Estado democrático es eficaz en sus garantías, así los logros sean progresivos, la violencia en su contra es terrorismo. No aceptamos la violencia para combatir el Gobierno ni para defenderlo. Ambas son terrorismo. La fuerza legitima del Estado cumple la exclusiva misión de defender a la comunidad y no puede utilizarse para acallar a los críticos".

"La democracia es el único camino para la emulación de las ideas. La democracia es nuestra oferta para que los fusiles sean sustituidos por la política y la Seguridad Democrática es el instrumento para que se haga politica sin armas y con el derecho de no ser asesinado".

"El deber impone impulsar la marcha de la nación. Debemos convertir la tristeza en energía creadora para que definitivamente renazca la esperanza".

“(...) carros bombas en Arauca, en la Fiscalía de Medellín, en el Club El Nogal de Bogotá tratan de detener el rumbo que nos hemos impuesto de recuperar la tranquilidad".

"Ese rumbo de recuperar la tranquilidad es irrenunciable. Nada ni nadie moverá el firme designio del pueblo de derrotar la violencia y el terrorismo, y el Gobierno, a pesar de los reveces, no será inferior al clamor de la comunidad".

"La cooperación ciudadana es necesaria, debemos fortalecerla. Todas las empresas privadas de seguridad tienen que colaborar estrechamente con la fuerza pública".

"Hay que informar por solidaridad, porque todos somos responsables de nuestra sociedad".

"Si todos ayudamos, la fuerza pública podrá desbaratar los planes de los terroristas".

“...rebasemos la cifra del millón y alcancemos 5 millones de cooperantes con la fuerza pública".

"44 millones rodeando las instituciones para derrotar la delincuencia".

"...el terrorismo que creció al amparo de la debilidad de autoridad, consentido por el discurso cómplice, la actitud débil y el escrito arrodillado de muchos demócratas". 
Análisis crítico del discurso sobre conflicto armado y desarrollo en los presidentes...

"Hemos formulado la petición de declarar terroristas estos hechos y a sus autores".

"Todas las familias colombianas tenemos que ponernos de pie contra la violencia y el terrorismo".

"Llamo a la unidad nacional contra la violencia y el terrorismo".

Fuente: Construcción propia a partir de los textos del corpus de análisis.

Por su parte, Santos señala el terrorismo como la acción de una minoría a la que le atribuye el carácter de "mala". De esta manera, opone a este reducido número de personas a los otros 45 millones de buenos colombianos. Esta minoría es también la que representa un obstáculo para la prosperidad (presentada aquí como desarrollo). Así, de manera implícita, el actor presenta dos únicos bandos sobre los cuales el receptor ha de tomar partido. Para aquellos que optan por ser parte de la minoría, se les auguran duras represalias, como las que se anuncian para los jefes terroristas, a quienes se les convertirá en objetivos de alto valor para localizarlos y neutralizarlos.

Es importante señalar que el actor ubica el terrorismo, a los grupos armados ilegales o violentos en el mismo orden o conjunto que otros fenómenos, como la pobreza o la corrupción, y los agrupa en una categoría amplia llamada "enemigos de Colombia". A estos objetivos se les combatirá y enfrentará de manera indistinta. Se trata de volver objetivo de alto valor a todos estos fenómenos para reducirlos.

Tabla 8. Unidades discursivas relevantes - Juan Manuel Santos -

Ideología y conflicto armado

\footnotetext{
“(...) una ínfima minoría que persiste en el terrorismo y el narcotráfico, en obstruir nuestro
camino hacia la prosperidad".

"A todas las organizaciones legales las defenderemos y a las ilegales las seguiremos combatiendo sin tregua ni cuartel".

"Yo aspiro, durante mi gobierno, a sembrar las bases de una verdadera reconciliación entre los colombianos".

“(...) superar confrontaciones estériles (...) odios sin sentido".

"Tenemos que asimilar la lección del pasado y aprender de los errores cometidos en esta brega por superar una confrontación que hace demasiado tiempo nos desgarra".

"(...) nuestros soldados, infantes de marina y policias que ahora mismo, hoy jahora mismo!, arriesgan sus vidas por proteger las de todos los colombianos".
} 


\section{"Čl'F='E 27}

ISSN: 0124-3551 / Año 17, No 27 / julio-diciembre / pp. 55-102

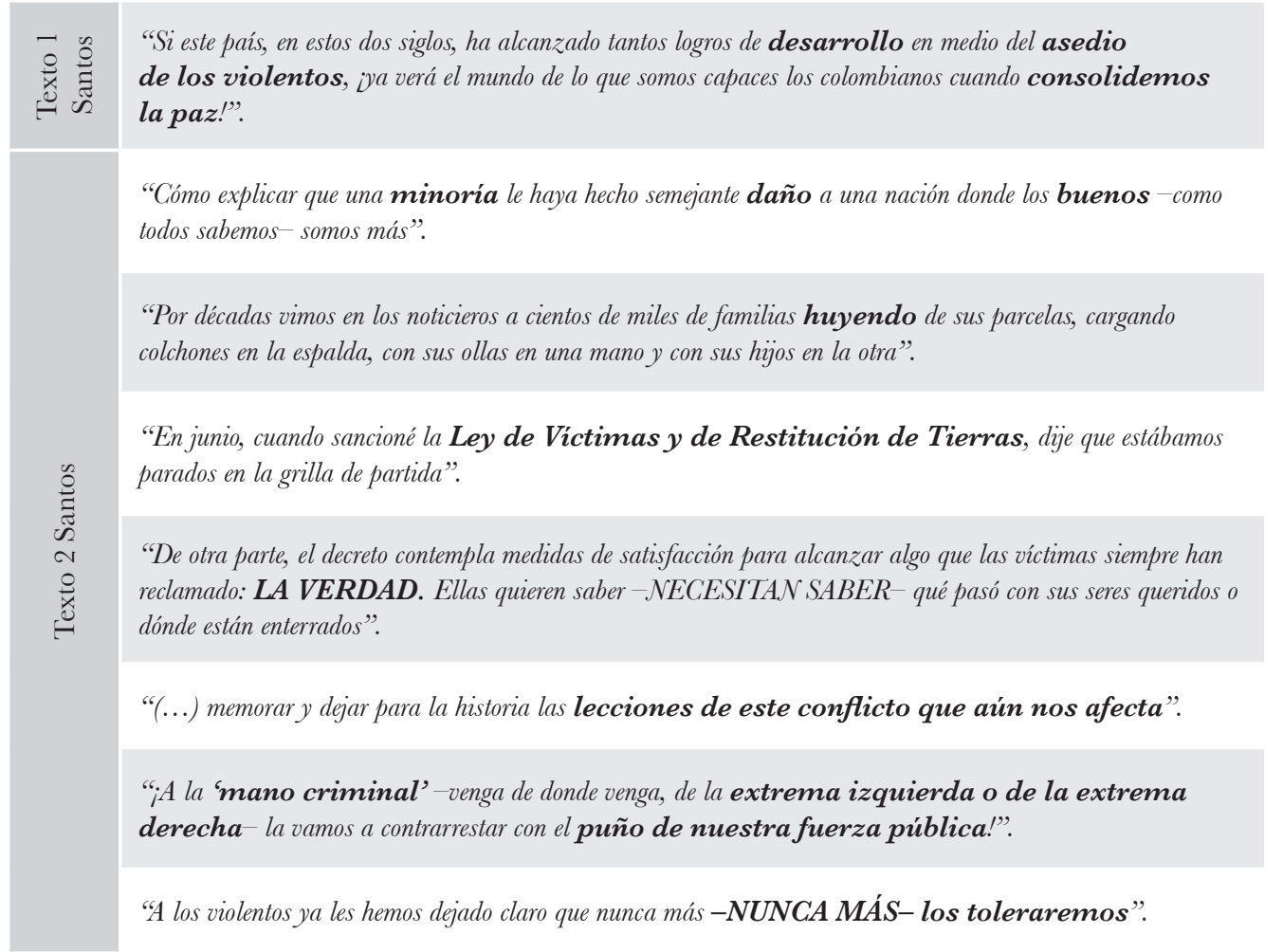

Fuente: Construcción propia a partir de los textos del corpus de análisis. 


\section{Conclusiones}

Después de hacer la presentación de los resultados obtenidos con la aplicación del instrumento de análisis, se llega a algunas conclusiones parciales que alimentan la discusión en torno al objetivo principal del estudio. He aquí dichas conclusiones:

\section{Identidad nacional:}

i) La identidad es condicionante y determinante del desarrollo en la medida en que permite armonizar las potencialidades de un Estado-Nación y la utilización de sus recursos, con los elementos culturales de la población que le constituye. La identidad nacional de los "colombianos" puede estar asociada con categorías de nivel de desarrollo (desarrollado, subdesarrollado, en vía de desarrollo, etc.). A su vez, diferentes subgrupos que conforman el universo Estado-Nación pueden tener diferencias en la forma de instituir elementos de identidad respecto de sus condiciones económicas, niveles y estrategias de participación política, así como de las relaciones establecidas entre los diferentes grupos. De esta forma, se entendería que no todos los subgrupos tendrían un mismo nivel de desarrollo y una identidad sobre este. Para los casos tanto de Uribe como de Santos, la estrategia consiste en desintegrar estas divisiones de los subgrupos y sus identidades particulares y apuntar hacia el establecimiento de una identidad nacional única, difiriendo en la modalidad, pero buscando armonizar de esta manera unos elementos culturales universalizados con el establecimiento de objetivos y prioridades de gobierno para un país "en vía de desarrollo".

ii) En los discursos se evidencia una intencionalidad de la acción política de los gobernantes en relación con los gobernados. Esta radica en legitimar prácticas sociales a partir de la generación de dinámicas de formación de identidad nacional como mecanismo de cohesión social. Para el caso del expresidente Uribe, se trata de la legitimación del ejercicio de la autoridad estatal mediante la política de Seguridad Democrática y el monopolio de las armas en cabeza de la fuerza pública; y para el caso del presidente Santos, se trata de la legitimación de la Constitución de un Gobierno de Unidad Nacional y la transición hacia la política de Prosperidad Democrática.

iii) Siguiendo a Freud (1921) cuando señala que la unión o el tipo de ligazón es justamente lo que caracteriza a una masa, es posible concluir que existe diferencia entre la idea de masa identificada en torno a elementos de cohesión nacional -como la ley, la autoridad y la obediencia a la norma, como es el caso de la estrategia discursiva del expresidente Uribe- ${ }^{-}$y aquella masa congregada mediante la referencia a la diversidad como posibilidad de encuentro y necesidad de unidad en el interior de una estructura de gobierno, como es el caso de la estrategia discursiva del presidente 
Santos. En el primer caso, los gobernados son convocados a adoptar una posición de obediencia o colaboración frente a un Estado que ejerce autoridad; en el segundo, son convocados a constituirse como un "nosotros", en contraposición a lo que queda por fuera, excluido de la unidad, como condición para el alcance de los objetivos del gobierno.

iv) En esta vía, las estrategias discursivas sobre identidad nacional son soportes de posibles relaciones entre conflicto armado y desarrollo. En el caso de los textos de Álvaro Uribe, estas estrategias fundamentan la idea de la conveniencia de una unidad popular legitimadora de conductas combativas de la población civil en cooperación con el Estado para derrotar el terrorismo como condición necesaria para obtener condiciones de desarrollo, entendidas estas como libertad, igualdad de oportunidades, empleo, inversión extranjera y crecimiento económico. Esta construcción discursiva se encuentra más cercana a una fórmula del tipo "conflicto armado como condición necesaria para la obtención de desarrollo". Por otra parte, los textos de Juan Manuel Santos indican un viraje del foco central hacia la identificación de la población con la "Unidad Nacional", como punto de encuentro de las diferencias en una estructura de gobierno y como soporte para la legitimación de la política de Prosperidad Democrática. En esta medida, se establece más una fórmula del tipo "desarrollo como solución al conflicto armado".

v) Wodak y Meyer (2003) describen un estudio propio en el que se buscó establecer un "análisis de las relaciones entre la construcción discursiva de la uniformidad nacional y la construcción discursiva de la diferencia conducente a la exclusión política y social de concretos grupos marginados" (Wodak y Meyer, 2003, p. 112). Para el caso del presente estudio, se puede concluir que las formaciones discursivas de los dos actores presentan una fuerte dinámica de inclusión/exclusión al establecer imaginarios y representaciones sociales de tipo nosotros/otros con base en elementos de cohesión social e identidad nacional. Expresiones como Unidad Nacional/oposición, minoría (terrorista)/45 millones de colombianos buenos, cooperantes/enemigos de la patria son apenas algunos de los ejemplos que sustentan esta afirmación.

vi) De acuerdo con el planteamiento de Wodak y Meyer (2003) respecto de los cuatro tipos de estrategias discursivas sobre identidad nacional, es posible concluir que los actores utilizan una mezcla de estas estrategias, inclinándose más por algún tipo. Así, ambos actores usan la estrategia constructiva en la medida en que promueven establecimiento de categorías de "nosotros" y "unidad" a partir de otras estrategias. Juan Manuel Santos, por ejemplo, recurre además a estrategias de transformación conservando algunos elementos de su predecesor Uribe, pero realizando algunas variaciones en busca de generar nuevos significados a una identidad nacional relativamente estable. Por su parte, Álvaro Uribe recurre a la estrategia de desmantelamiento, recurriendo a lo que, según mi interpretación, sería un nuevo tipo de 
estrategia, el restablecimiento, dado que busca prescindir de elementos actuales interpretados como nocivos y recuperar otros ya perdidos en la historia, como la ley, la norma, la obediencia a la autoridad, etc.

\section{Estructuras de poder y modelos de desarrollo:}

i) El poder implica la posibilidad de mando y ejercicio de la autoridad, denota las capacidades, posibilidades y facultades que tiene un sujeto o grupo de sujetos (en este caso el gobierno) para realizar tomas de decisiones y ejecutar acciones referidas a la asignación y gasto de recursos en el funcionamiento del Estado-Nación. Este funcionamiento incluye la delimitación de los modelos de desarrollo que determinarán el devenir de su sociedad. El sujeto de poder requiere un andamiaje para realizar este ejercicio de autoridad. Estas estructuras son las instituciones, las leyes, el mercado y la información. Así se evidencia una intencionalidad discursiva por parte del actor Álvaro Uribe para legitimar al Estado como único portador y ejecutor del poder, estableciendo relaciones desiguales con otros sectores sociales. El empoderamiento se da solo para algunos sectores, como el Estado, sus Fuerzas Militares y el sector económico. La estrategia de incentivar informantes en la sociedad civil obedece a esta lógica, con la que se busca dotar al Estado de la mayor cantidad de información para su uso, mientras el informante se ubica en el lugar de instrumento y no de sujeto empoderado. Por su parte, Juan Manuel Santos utiliza la estrategia discursiva de "unidos somos más fuertes" y apela a la necesidad de lograr una coalición para alcanzar mejores dinámicas de desarrollo. La estructura de poder es la Unidad Nacional misma, con la que también se establecen relaciones desiguales de poder con aquellos sectores que se ubican en su exterior.

ii) Las estructuras de poder para implementar modelos de desarrollo por parte de los expresidentes tienen base, principalmente, en la instalación de discursos hegemónicos. Por medio de este mecanismo, se realiza un ejercicio desigual del poder y se busca el dominio o la imposición de unas ideas de desarrollo sobre otras y la alienación de los gobernados a estas. En correspondencia con lo planteado por Van Dijk (2003), el establecimiento de un discurso hegemónico busca estructurar o modificar esquemas mentales colectivos o representaciones sociales. De esta manera, en una sociedad se hace posible, por ejemplo, una idea arraigada de desarrollo, entendido como tranquilidad o facilidad para viajar por las vías del país.

iii) Existen otras estructuras de aplicación del poder que permiten la efectiva implantación del modelo de desarrollo. Para el caso de Álvaro Uribe Vélez, se trata de la acción efectiva y real del aparato de fuerza pública legitimado por el discurso de autoridad y Seguridad Democrática, pues en la confrontación misma entre la fuerza pública y grupos armados ilegales se establece una pugna entre la defensa o imposición de ideas o modelos de desarrollo. Para el caso de Juan Manuel Santos, 
aunque también existen alusiones a la necesidad de adelantar acciones de confrontación, es más significativa la idea de conformación de una estructura de gobierno de "Unidad Nacional" que garantice que las propuestas de desarrollo, enmarcadas en la política de Prosperidad Democrática, tengan respaldo y aprobación en el Congreso y otras instancias de la vida política, incluida la percepción y aceptación ciudadana.

iv) La polarización se constituye como otra estructura de poder que opera en doble vía respecto de la producción discursiva sobre el desarrollo. Por un lado, la emisión de los discursos tiene efectos de polarización en los gobernados y esta, a su vez, puede generar nuevas elaboraciones de discursos, ya sean de respaldo o resistencia a nivel de población civil, grupos armados ilegales o esfera política. Como se ha señalado en anteriores apartados, en los discursos de los actores, en este estudio, se utilizan estrategias discursivas que emplean estructuras del tipo nosotros/ellos. Estas construcciones discursivas son focos de procesos de polarización que son resultado de aplicaciones de estrategias de uso poder por parte de los mismos actores. Así, es posible identificar construcciones del tipo "Nosotros, los de la Unidad Nacional y la Prosperidad Democrática" o "Ellos, los que obstruyen el desarrollo del país".

v) Para el caso de los discursos de Álvaro Uribe, las ideas de desarrollo se asocian con el modelo de "crecimiento económico", basado en ajustes fiscales, inversión extranjera y liberalismo económico, que se espera tengan una incidencia positiva en la generación de empleo. Además, el actor presenta una serie de instrumentos para la construcción de equidad, como la revolución educativa, la ampliación de la seguridad social, el impulso de la economía solidaria, el manejo social del campo, el apoyo a la pequeña y mediana empresa y el mejoramiento de la calidad de vida urbana. Estas condiciones de estabilidad económica dependen de la cohesión social en torno a elementos como la firmeza y la autoridad en la dirección por parte del Estado. De esta manera, se podría concluir que, para el caso de Álvaro Uribe, el modelo de desarrollo planteado en los discursos está más cercano al modelo neoliberal, siguiendo de cerca los postulados de las políticas del Consenso de Washington. Así, resalta el crecimiento económico como única fuente de ingresos perdurable para el Estado, con un control fuerte de este último sobre las dinámicas económicas del país.

vi) Para el caso de Juan Manuel Santos, aunque en los textos aquí analizados también se refiere al crecimiento económico, es más común en sus discursos la alusión al término "desarrollo económico". En los discursos de Juan Manuel Santos, el crecimiento económico no es ilimitado, sino que es directamente proporcional al crecimiento de las necesidades de la población. Por otro lado, es importante diferenciar el "crecimiento económico" del "desarrollo económico". El primero se ocupa tan solo de los incrementos de la productividad de una nación, que representan, a su 
vez, incrementos del PIB. El segundo se refiere a cambios estructurales en la economía, que garanticen la satisfacción de las necesidades materiales y no materiales de los integrantes de una nación, de manera estable y constante en el tiempo. Estos elementos de desarrollo económico estarán orientados en los discursos hacia la formulación de la política de Prosperidad Democrática, que podría interpretarse como más cercana al desarrollo humano en la medida en que se establecen relaciones de aporte del crecimiento económico hacia la satisfacción de las necesidades humanas y la generación de capacidades.

vii) La Ley de Víctimas y Restitución de Tierras - 1448/11, con la cual el Estado reconoce la existencia de un conflicto armado interno, de acuerdo con los lineamientos del DIH, también representa el reconocimiento de las víctimas producto del mismo conflicto. Las estrategias discursivas del presidente Juan Manuel Santos convocan a la población a identificarse en torno a la necesidad de emprender procesos de desarrollo dirigidos a un sector poblacional en particular, identificado como vulnerable por haber sufrido los embates de la guerra. Estos procesos permiten transformaciones de los efectos del conflicto hacia expresiones de "prosperidad" o posibilidades de desarrollo.

viii) Las construcciones discursivas del presidente Juan Manuel Santos respecto de las propuestas de desarrollo para el país coinciden con los planteamientos del Informe de Desarrollo Humano para Colombia - PNUD 2003 sobre el origen del conflicto armado en el país. Según este informe, el conflicto surgió con base en relaciones desiguales de desarrollo, en el marco de una lógica de centro-periferia, dado que se establecieron regiones aisladas económica, política y socialmente de los centros de desarrollo. Estas regiones aisladas se caracterizaron por un vacío de presencia estatal, el cual fue copado por la aparición de los grupos armados ilegales. Así, el informe plantea el incremento de las posibilidades de desarrollo en la periferia como solución al conflicto armado. Juan Manuel Santos usa como constructo discursivo la idea de "cerrar la brecha de desarrollo entre las regiones de la periferia y el centro del país". Este es un elemento propio de la escuela estructuralista del desarrollo y posiblemente demarca la puesta en marcha de posteriores reformas como las realizadas al Sistema General de Regalías, con las que se busca una distribución más equitativa para las regiones, de las riquezas provenientes de la explotación de recursos naturales en el país.

\section{Sistemas ideológicos sobre conflicto armado y desarrollo:}

i) Es posible concluir que, con las referencias ideológicas en los discursos aquí analizados, se pretende lograr que un colectivo poblacional tome posición respecto de las posibilidades identificadoras existentes en relación a la ocurrencia del conflicto 
armado en el país. Esta toma de posición es el fin último de la operación de la ideología en el discurso.

ii) Álvaro Uribe convoca a respaldar popularmente un proyecto político de derecha, cuyos principios básicos se sustentan en el orden, la institucionalidad y las libertades privadas. Desde este terreno, el actor manifiesta su oposición a otros discursos políticos que, según él, desde la democracia asumen posturas débiles, laxas y "arrodilladas", las cuales se han constituido como caldo de cultivo para el aumento del accionar terrorista. Precisamente, este es el escenario desde el cual se legitima la idea de un enemigo único para la nación, el "terrorismo", despojado de cualquier rasgo de beligerancia o carácter político. Con esto también se da la negación de la existencia de un conflicto armado interno en Colombia y, de paso, la invisibilización de la generación de víctimas producto de este.

iii) En los textos de Álvaro Uribe, se evidencia una argumentación respecto al conflicto armado que va en dos vías. Por un lado, se encuadra con el postulado de Hirschman (1994) respecto a los conflictos indivisibles. Existe una fuerte construcción discursiva que elabora categorías de identidad social excluyentes, se hace fuerte la idea de que se gana o se pierde y se reduce la referencia a posibilidades de negociación entre las partes. Por otro lado, el conflicto armado es presentado como solución, siendo condición necesaria para acabar con las incompatibilidades que representa el enemigo. Por ello se requiere ganar. En términos coloquiales, sería como afirmar: "Este conflicto no tiene solución. La única solución es confrontar y ganar".

iv) Esta estrategia discursiva de Álvaro Uribe tiene varios efectos. En primer lugar, legitimar un uso coloquial del término terrorismo y que se constituya como natural y obvio en la sociedad, pero que esté desprovisto de cualquier contenido jurídico o legal, dado que se desconoce la competencia del DIH para indicar la existencia o no de un conflicto armado. En segundo lugar, generar una categorización excluyente entre conflicto armado y terrorismo, en la que no existe posibilidad de una presentación mixta de estas dos condiciones. Y, por último, la convocatoria populista de tomar partido en el marco de una polarización entre buenos y malos. Los primeros, el Estado con la autoridad para tener el monopolio de las armas, y que es víctima del terrorismo. Los segundos, los terroristas o grupos violentos a quienes se les debe imponer una resistencia. Así, desde su investidura de líder, Uribe convoca a la "unidad nacional contra la violencia y el terrorismo" e insta a quienes se identifican con dicha fórmula a participar activamente en la lucha para vencer a estos grupos. La ideología determina actitudes de grupo. La actitud de este grupo debe ser la de informar, colaborar y cooperar con las autoridades estatales.

v) Las construcciones discursivas de Juan Manuel Santos, aunque también refieren a la categoría terrorismo, no excluyen la posibilidad de reconocimiento de la categoría 
Análisis crítico del discurso sobre conflicto armado y desarrollo en los presidentes...

Carlos Pabón

conflicto armado. Con la formulación de la Ley de Víctimas y Restitución de Tierras - 1448/11 hay un reconocimiento implícito de la condición de conflicto armado en el país de acuerdo con los principios establecidos por el DIH. En conclusión, la ley se constituye también como una nueva producción discursiva sobre el conflicto armado y sus efectos. Sin embargo, los textos del actor presentan también una estrategia de polarización entre buenos/malos, que para el caso coinciden respectivamente con los constructos mayoría/ minoría. La minoría, los terroristas o violentos que insisten en su accionar, y la mayoría, los otros 45 millones de buenos colombianos.

\section{Referencias}

Bartos, O., \& Werh, P. (2002). Using conflict theory. London: Cambridge University Press.

Becker, G. (1968). Crime and punishment: An economic approach. Fournal of Political Economy, 76(2), 169-222.

Bourdieu, P. (2008). ¿Qué significa hablar? Economía de los intercambios lingüísticos. Madrid: Akal.

Buitrago, D. (2013). Evolución de la economía colombiana en el periodo 2002-2010. Recuperado de: $\quad$ http://201.221.128.62:3000/Pagina/images/stories/investigacion/El\%20 Crecimiento\%202002.pdf

Buvinic, M., Morrison, A., \& Shifter, M. (1999). La violencia en América Latina y el Caribe: Un marco de referencia para la acción. Washington D. C.: Banco Interamericano de Desarrollo. Recuperado de goo.gl/Bylg4M

Camacho, A. (1991). El ayer y el hoy de la violencia en Colombia: Continuidades y discontinuidades. Análisis Político, 12. Recuperado de goo.gl/tUnlVc

Center for the Study of Civil Wars, International Peace Research Institute, Oslo (PRIO). (2013). UCDP/PRIO Armed Conflict Dataset Codebook. Recuperado de http:// www.pcr.uu.se/digitalAssets/124/124920_1codebook_ucdp_prio-armed-conflictdataset-v4_2013.pdf

Clavijo, B. y Morera, L. (2010). Elecciones presidenciales Colombia 2010. Recuperado de goo. $\mathrm{gl} / \mathrm{ikASNO}$

Comité Internacional de la Cruz Roja - CICR. (2008). ¿Cuál es la definición de "conflicto armado" según el derecho internacional humanitario? Recuperado de http://www.icrc.org/ spa/assets/files/other/opinion-paper-armed-conflict-es.pdf 
ISSN: 0124-3551 / Año 17, No 27 / julio-diciembre / pp. 55-102

Doucet, I. (1998). Buscando la paz del mundo: Manual de recursos para la transformación del conflicto. Londres: Semilla.

Escobar, A. (2005). El "postdesarrollo" como concepto y práctica social. En D. Mato (coord.), Politicas de economía, ambiente y sociedad en tiempos de globalización (pp. 17-31). Caracas: Facultad de Ciencias Económicas y Sociales - Universidad Central de Venezuela. Recuperado de goo.gl/e1FGDR

- (2007). La invención del tercer mundo. Construcción y deconstrucción del desarrollo. Caracas: Fundación Editorial El Perro y La Rana.

- (2010). Una minga para el postdesarrollo: Lugar, medioambiente y movimientos sociales en las transformaciones globales. Bogotá D.C: Ediciones Desde Abajo. Recuperado de http://www.cronicon.net/paginas/Documentos/No.8.pdf

Esteva, G. (1996). Desarrollo. En W. Sach (ed.), Diccionario del desarrollo. Una guía del conocimiento como poder (pp. 52-78). Lima. PRATEG.

Fairclough, N. (1989). Language and power. New York: Longman Group.

Fisas, V. (1998). Cultura de paz y gestión de conflictos. Barcelona: Icaria Editorial S. A.

- (2005). Abordar el conflicto: La negociación y la mediación. Revista Futuros, 3(10). Recuperado de goo.gl/kn9lpb

- (2010). El proceso de paz en Colombia. Quaderns de Construcció de Pau, 17. Recuperado de http://escolapau.uab.es/img/qcp/procesos_paz_colombia.pdf

Freud, S. (1986 [1921]). Psicología de las masas y análisis del yo. Buenos Aires: Amorrortu.

Galtung, J. (1990). Cultural Violence. Journal of Peace Research, 27(3), 291-305.

Gonzáles, F. (2006). El fenómeno político de Álvaro Uribe Vélez. Recuperado de http://www. institut-gouvernance.org/es/analyse/fiche-analyse-245.html

Gunder-Frank, A. (1963). América Latina: Subdesarrollo o revolución. México: Editorial ERA.

Hirschman, A. (1994). Social conflicts as pillars of democratic market society. Political Theory, 22(2), 203-218.

Jaramillo, J. (2005). La reelección presidencial inmediata en Colombia. Revista Nueva Sociedad, 198, 15-31. Recuperado de http://www.nuso.org/upload/articulos/3268_1.pdf 
Análisis crítico del discurso sobre conflicto armado y desarrollo en los presidentes...

Carlos Pabón

Martínez, A. O. (2001). Economía, crimen y conflicto. Bogotá D.C.: Universidad Nacional de Colombia.

Max-Neef, M. (1986). La economía descalza. Buenos Aires: Editorial Nordan. . (1993). Desarrollo a escala humana. Montevideo: Icaria.

Medina, E. (2013). De "primavera silenciosa" a "desarrollo sostenible". Un análisis crítico del discurso sobre el desarrollo del asunto medioambiental 1962-1987. Recuperado de http://www. mdh.se/hvv/personal/soa/ema01/min-undervisning-1.9148?l=en_UK

Mogrovejo, R. J. (2010). Desarrollo: Enfoques y dimensiones. Bolivia: Centro Bolivianos de Estudios Multidisciplinarios. Recuperado de http://cebem.org/cmsfiles/publicaciones/Desarrollo.pdf

Moncayo, E. (2002). Nuevos enfoques de politica regional en América Latina: El caso de Colombia en perspectiva histórica. Tendencias del desarrollo regional en Colombia. Polarización, apertura y conflicto (Serie Archivos de Economía. Separata n. ${ }^{\circ} 6$ de 7. Documento de trabajo n. ${ }^{\circ}$ 199). Bogotá: DPN. Recuperado de https://colaboracion.dnp.gov.co/CDT/ Estudios\%20Econmicos/199.pdf

Moser, C. (2000). Violence in Colombia. Building sustainable peace and social capital. Washington D. C.: Banco Mundial.

Pardo, N. (2005). Representación de los actores armados en conflicto en la prensa colombiana. Forma y Función, 18, 167-196. Recuperado de http://www.redalyc.org/ articulo.oa?id=21901807

- (2007). Cómo hacer análisis crítico del discurso. Una perspectiva latinoamericana. Santiago de Chile: Frasis.

Ploughshare Project. (2014). Colombia (1964 - First Combat Deaths). Annual Armed Conflict Report. Recuperado de goo.gl/JzTWOJ

Ploughshare Project. (2014). Defining Armed Conflict. Recuperado de goo.gl/MPbIrQ

Preston, P. (1999). Descolonización, guerra fría y elaboración de la teoría de la modernización. En Una introducción a la teoría del desarrollo (pp. 187-216). México: Siglo XXI Editores.

PNUD. (2003). El conflicto, callejón con salida. Informe Nacional de Desarrollo Humano. Colombia: PNUD. Recuperado de http://www.fuac.edu.co/download/AREAS/13dhu.pdf 
ISSN: 0124-3551 / Año 17, No 27 / julio-diciembre / pp. 55-102

Puerta, E. y Vásquez, M. (2012). Concepto de resiliencia. Caminos de Resiliencia, 1(2), 1-4. Recuperado de goo.gl/iROahB

Ricoeur, P. (1995). Teoría de la interpretación. Discurso y excedente de sentido. México D. F.: Siglo XXI Editores.

Sánchez, F. y Díaz, A. (2005). Los efectos del conflicto armado en el desarrollo social colombiano, 1990-2002. Bogotá: Centro de Estudios sobre Desarrollo Económico (CEDE), Facultad de Economía, Universidad de los Andes.

Sen, A. (2000). Desarrollo y libertad. Buenos Aires: Planeta.

- (2002). ¿De qué se trata el desarrollo? En G. Meier y J. Stiglizt, Fronteras de la economía del desarrollo. El futuro en perspectiva (p. 594). Washington: Banco Mundial en coedición con Alfaomega Colombiana S. A.

Uribe, M. (2013). La nación vetada: Estado, desarrollo y guerra civil en Colombia. Bogotá: Universidad Externado de Colombia.

Van Dijk, T. A. (1999). El análisis crítico del discurso. Anthropos, 186, 23-36. Recuperado de http://www.discursos.org/oldarticles/El $\% 20 \mathrm{an} \% \mathrm{E} 1 \mathrm{lisis} \% 20 \mathrm{cr} \% \mathrm{EDtico} \% 20$ $\operatorname{del}^{\%} \% 20$ discurso.pdf

- (2003). La multidisciplinariedad del análisis crítico del discurso: Un alegato a favor de la diversidad. En R. Wodak y M. Meyer, Métodos del análisis crítico del discurso (pp. 143-177). Barcelona: Gedisa.

. (1996). Análisis del discurso ideológico. Versión, 6, 15-43. Recuperado de http://www.discursos.org/download/articles/

. (1998). Texto y contexto: Semántica y pragmática del discurso. Madrid: Cátedra S. A.

Vargas, A. (2004). El gobierno de Álvaro Uribe: Proyecto y resultados. Nueva Sociedad, 192, 85-97. Recuperado de http://nuso.org/media/articles/downloads/3210_1. pdf

Vasilachis, I. (2006). Estrategias de investigación cualitativa. Barcelona: Gedisa.

Wallensteen, P. (2002). Undestanding conflict resolution. War, peace and the global system. London: SAGE Publications.

Wodak, R., \& Meyer, M. (2003). Métodos del análisis crítico del discurso. Barcelona: Gedisa. 